FINAL TECHNICAL REPORT

for

DOE Grant DE-FG02-89ER45396

\title{
RADIATION-DISORDER AND APERIODICITY \\ IN IRRADIATED CERAMICS
}

for the period

22. June $1989-21$ June 1992

\author{
submitted by \\ Professor Linn W. Hobbs \\ Department of Materials Science and Engineering \\ Massachusetts Institute of Technology \\ Cambridge, MA 02139 \\ (617) 253-6835 \\ FAX: (617) 258-7874
}
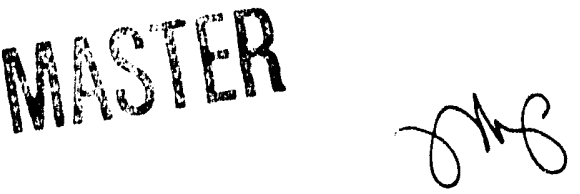


\section{TABLE OF CONTENTS}

1. INTRODUCTION $\ldots \ldots \ldots \ldots \ldots \ldots \ldots \ldots \ldots \ldots \ldots \ldots$

2. THE METAMICT TRANSFORMATION OF IRRADIATED CERAMICS . . . 3

3. MODELLING THE METAMICT TRANSFORMATON OF SILICA $\ldots \ldots 6$

3.1 The Metamict Transformation in Quartz .............. 9

3.2 Combinatorial Geometry of Aperiodic Silica ............. 13

4. ELECTRON DIFFRACTION FROM APERIODIC STRUCTURES . . . . 36

4.1 Theory of Energy-Filtered Electron Diffraction $\ldots \ldots \ldots \ldots \ldots$

4.2 Preliminary Results and Discussions $\ldots \ldots \ldots \ldots \ldots \ldots \ldots$

5. METAMICT TRANSFORMATION IN POLYPHOSPHATE CERAMICS .. 55

5.1 Current Results from Lead Pyrophosphate and Lead Metaphosphate . 57

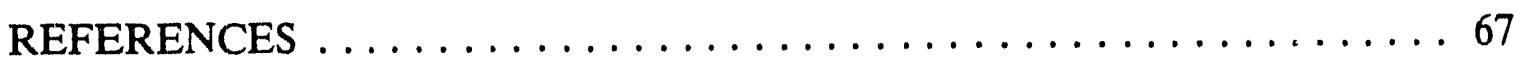

PUBLICATIONS ............................ 79

\section{DISCLAIMER}

This report was prepared as an account of work sponsored by an agency of the United States Government. Neither the United States Government nor any agency thereof, nor any of their employees, makes any warranty, express or implied, or assumes any legal liability or responsibility for the accuracy, completeness, or usefulness of any information, apparatus, product, or process disclosed, or represents that its use would not infringe privately owned rights. Reference herein to any specific commercial product, process, or service by trade name, trademark, manufacturer, or otherwise does not necessarily constitute: or imply its endorsement, recommendation, or favoring by the United States Governmenl or any agency thereof. The views and opinions of authors expressed herein do not necessarily state or reflect those of the United States Government or any agency thereof. 


\section{INTRODUCTION}

This final technical report documents the accomplishments of the program of research entitled "Radiation Disorder and Aperiodicity in Irradiated Ceramics" for a program of research funded under DOE Grant DE-FG02-89ER45396 for the period June 22, 1989 - June 21, 1992. This research forms the latest part on an on-going program, begun at MIT in 1983 under DOE support, which has had as its objectives investigation of the responses in radiation environments of ceramics heavily-irradiated with electrons, neutrons and ions, with potential applications to fusion energy technology and high-level nuclear waste storage. Materials investigated have included $\mathrm{SiO}_{2}, \mathrm{MgAl}_{2} \mathrm{O}_{4}, \mathrm{Al}_{23} \mathrm{O}_{27} \mathrm{~N}_{5}, \mathrm{SiC}, \mathrm{BeO}$, $\mathrm{LiAlO}_{2}, \mathrm{Li}_{2} \mathrm{ZrO}_{3}, \mathrm{CaTiO}_{3}, \mathrm{KTaO}_{3}$ and $\mathrm{Ca}(\mathrm{Zr}, \mathrm{Pu}) \mathrm{Ti}_{2} \mathrm{O}_{7}$. The radiation responses of many of these ceramic materials, and non-metals in general, have been reviewed by Clinard and Hobbs [1] The issues involved have been the subject of a series of DOE-sponsored workshops [2-5] in which the principal investigator has participated, the most recent of which [5] was held in August 1990.

The program initially proposed for 1989 had as its major objectives two main thrusts: 1) research on defect aggregation in irradiated non-oxide ceramics, and 2) research on irradiation-induced amorphization of network silicas and phosphates. Austerities in the DOE-BES budget rendered only one of these thrusts fiscally viable for the period 1989-92, and the second was selected as the principal focus of the supported work. The subject of amorphization, about which much less is known about aggregate defect responses of crystalline ceramics, represents one of the major topics cited by the recent DOE workshop in its review of relevant radiation effects in non-metals and is introduced in Section 2. The work on silica has involved two approaches, the first being continued modelling of the topological possibilities inherent in fully- but aperiodically-connected silica nets, and the second an experimental assessment of aperiodic structures, produced by cooling through the glass transition and by electron, ion and neutron irradiation, using energy-filtered electron diffraction techniques. Progress on these two fronts is described in Sections 3 and 4 of this proposal. Proposed work on network phosphates was originally envisioned as a collaborative program with Dr. Lynn Boatner at Oak Ridge National Laboratory, who had been investigating structural characteristics of crystalline and glassy lead pyrophosphates $\left(\mathrm{Pb}_{2} \mathrm{P}_{2} \mathrm{O}_{7}\right.$, 
or $2 \mathrm{PbO} \cdot \mathrm{P}_{2} \mathrm{O}_{5}$ ). Because the collaboration did not develop, an independent effort was instead mounted and expanded to include production, irradiation and evaluation, not only of crystalline and glassy lead pyrophosphates, but also of a second $\mathrm{Pb}$ phosphate composition, the metaphosphate $\left(\mathrm{PbP}_{2} \mathrm{O}_{6}\right.$, or $\left.\mathrm{PbO} \cdot \mathrm{P}_{2} \mathrm{O}_{5}\right)$, and intermediate compositions as well. Accomplishments in this study are detailed in Section 5.

Two fundamental concerns arising in the study of radiation responses of ceramics are 1) how displacements are created and 2) how the resulting point-defect disorder is accommodated. Irradiation of solids with fast electrons or very light ions produces relatively isolated Frenkel defects, with a uniform distribution, in widely-separated direct knock-on (ballistic) events, while neutron and heavier-ion irradiation generate dense localized collision cascades within which the structural disorder is anomalously high. Ceramics which are substantially insulating offer a third prospect, radiolysis, by which the electronic stopping power (for photons, as well as for electrons and ions) can contribute atomic displacements by indirect processes involving intermediate localized electronic excitations [6]. For many ceramics, e.g. halides, silicates) radiolysis competes favorably with direct displacement processes. What distinguishes most ceramics (with the exception of elemental semiconductors, like $\mathrm{Si}$ or $\mathrm{Ge}$, and diamond) from metals is that they are compounds with strong site preference and prohibitively high antisite defect energies, which are the consequence of substantial ionicity; $\mathrm{Si}, \mathrm{Ge}$ and diamond (and to some extent $\mathrm{SiC}$ ) are distinguished by the strongly directed nature of their covalent bonding. Polyatomicity and site order additionally introduce the possibility of non-stoichiometry in the displacement spectrum, which has its extreme confirmation in solids, such as halides [7] and $\mathrm{SiO}_{2}$ [8], which suffer radiolytic displacement on only a single sublattice. Structural units are important in ceramics, both conceptually and mechanistically, and are often vigorously maintained in the subsequent response to extensive irradiation-induced disorder.

The conventional (i.e. traditionally-studied) mode of accommodating irradiation disorder is accumulation of point defects at fixed, local sinks, such as dislocation loops, voids or precipitated phases. These aggregate defect sinks are catalogued in some detail by Clinard and Hobbs [1] for a representative range of ceramics studied to date and were an early focus of this program. A second important radiation response, the crystal-to-glass 
transformation known geologically as the metamict transformation [9] or, less accurately, amorphization [10], is especially prevalent in ceramic systems (including semiconductors [11]) but also observed in intermetallic compounds [12]. It differs fundamentally from the more usual response of aggregation of irradiation-induced point defects into localized aggregate sinks in that the result is ultimately global, the entire solid adopting a uniformly (though not necessarily homogeneously) defective state. Because initially aperiodic solids (e.g. glasses) are also known to alter their structure (as evinced from density changes) under irradiation [13], it is suggested here that the metamict states of a solid comprise those aperiodic structures which are metastable under particular irradiation conditions, irrespective of the initial structural configuration (crystalline polymorph or glass). The term metamict is preferable to the somewhat inaccurate epithet amorphous, because there is abundant evidence that significant medium-range order exists in glasses, and especially radiation glasses [14]. Aperiodic is better still, but because no suitable corresponding verb expressing transformation under irradiation to an aperiodic state exists, the terms amorphize and amorphization will continue to be used, advisedly; metamictization is just too awkward. Radiation glass is not always appropriate, because metamict material has not necessarily been shown to exhibit a glass transition temperature, although again the term will continue to be used advisedly.

\section{THE METAMICT TRANSFORMATION OF IRRADIATED CERAMICS}

During amorphization, long-range ordered periodicity (though not necessarily shortrange or even medium-range order) is progressively lost. The transformation is often complete at surprisingly small displacement doses, $0.1-1 \mathrm{dpa}$, whether the transformation results from accumulation of point-defect disorder (as occurs in electron-irradiated silicates [8] or Si implanted with light ions [15]) or overlap of dense collision cascades. A critical energy density (of order 5-10 eV/atom) appears to be required, at least for ion bombardment of semiconductors [11]. The structure of radiation glasses is demonstrably different from that of their melt-derived counterparts, and often appears to differ from the crystalline analogues by only small misalignments of the structural coordination units [23]. 
There is still no understanding of why some structures are susceptible to amorphization and others not. Alkali halides, for example, and most metals (with the axception of ordered intermetallic alloys) can suffer hundreds of dpa, even at $4 \mathrm{~K}$, without surrendering their crystallinity. Alumina $[16,17]$ and other oxide ceramics with more complex structures, such as $\mathrm{ABO}_{3}$ perovskites [18,19], $\mathrm{A}_{2} \mathrm{~B}_{2} \mathrm{O}_{7}$ pyrochlores [20-22], $\mathrm{ABC}_{2} \mathrm{O}_{7}$ zirconolite [22-24] and $\mathrm{ASiO}_{4}$ orthosilicates such as zircon [21,25-28] lose crystallinity under heavy-jon implantation or $\alpha$-recoil damage at about $1 \mathrm{dpa}$. Network silicates (such as quartz [29]), most mineral silicates [30] and complex framework silicates (such as zeolites [31]) readily amorphize as a consequence of radiolytic displacements in an electron beam [32], while other covalent network structures, such as $\mathrm{Si}[15,33]$ and some apatite silicates $[34,35]$, capitulate only under ion bombardment, and still others, like SiC [17,36], only under heavy ion bombardment.

Matzke [37], following the earlier attempt by Naguib and Kelly [38], has formulated three criteria, based on crystal structure, bond type and a thermal spike model, to predict whether or not amorphization occurs in a given material. Typically, largely ionic cubic subst nces were predicted to remain crystalline, whereas materials with complex anisotropic struct res, covalent bonding and high recrystallization temperatures were predicted to amor hize. Despite generally observed adherence to these phenomenological guidelines, little $\mathrm{f}$ rogress has been made on their theoretical underpinnings in the intervening half decadie [39].

Some of these trends can, however, be explained in at least general terms. Certainly, the covalency criterion is related to the lower coordination expected of directed covalent bonds, and the lower coordination in turn to ease of glass formation [40], which has to do with cornbinatorial aspects of structural connectivity. $\mathrm{Si}$, with 4-fold coordination, and $\mathrm{SiO}_{2}$ with $[4,2 \mid$ connectivity, form network structures whose possibilities for restructuring are much richer thian for close-packed simple ionic structures. We have come some way in describing what there possibilities are in network silicas over the three years since Matzke's second review [3], and these results are reviewed in Section 3.

The structural complexity issue is related to ease of recrystallization, which is in turn related to (lefect diffusion and recovery processes. The spatial extent of disorder remaining 
in collision cascades (or "damage tracks") is governed by the extent of epitaxial recrystallization from the surrounding matrix template, which is why we have consequently pursued study of the solid-phase epitaxial recrystallization of amorphized ceramics, notably the peroskites $\mathrm{CaTiO}_{3}[18]$ and explored the effect of irradiation temperature, annealing temperature and dose rate in amorphization of zirconolite [46].

Though there is at present little information on the structure of metamict states, there exist two schools of thought regarding the mechanism of their formation. The first [33], deriving largely from observations of the metamict transformation under heavy-ion implantation (but also including heavy $\alpha$-recoil ions in actinide-containing natural minerals or doped ceramics), holds that order within individual collision cascades is wholly destroyed, and that the increasing overlap of disordered (or reordered) cascades progressively consumes unaffected material until the whole is transformed. Since amorphization is observed in some materials (e.g. Si) even with light ions, where cascades are small or substantially absent, a second school contends that the metamict rearrangement takes place (perhaps precipitously, and so giving rise to dose-rate and temperature dependencies) when a critical energy density [11] or critical point defect disorder level [38] accumulates. This second approach has particular applicability to the role of irradiation-induced chemical disorder in intermetallic compounds which precedes, and ostensibly precipitates, amorphization [41], whereas only topological disorder has any relevance for monatomic solids like silicon or for ceramic compounds with anti-site proscription. Synergism of the two mechanisms may, of course, be important [42], and grosser yardsticks, such as the critical energy deposited/atom [11], are frequently invoked. Diffusional rearrangement of atoms in the "thermal spike" phase of displacement cascades (time $\sim 100 \mathrm{ps)}$ ) has regained acceptance as a model for explaining gross disorder within cascades, even in metals [43], but especially in ceramics where electronic excitations are not quickly delocalized and the large energy densities $(\sim 10 \mathrm{eV} /$ aton $)$ present are in excess of those at the melting point. It is notable that "holes" can be "drilled" in $\mathrm{Al}_{2} \mathrm{O}_{3}$ and other ceramics by the intense ionization field of an electron beam [44]. Coghlan and Clinard [45], in turn, have emphasized the importance of redamage in overlapping damage tracks which causes relaxation to a second, more stable metamict state and so explains earlier density and stored energy results for 
metamictization of $\mathrm{CaPuTi}_{2} \mathrm{O}_{7}$ at $350 \mathrm{~K}$ and $575 \mathrm{~K}$ [46]. Weber $[27,28]$ has shown that the observed sigmoidal amorphization kinetics of Pu-doped (and natural) zircon are incompatible with direct amorphization within individual cascades and best fit a model of multiple cascade overlap.

Our own suspicions, based on our experience with tetrahedral networks, defect fluorite, perovskite and pyrochlore structures, is that what is important for amorphization are the structural options available to a given compound. When alternative (even higher energy) structural forms are possible, for example polymorphic forms or particularly where structures incorporate so-called "structural vacancies", then in the wave of irradiation disorder multiple medium-range ordered atomic rearrangements can occur during the thermal phase of recovery which may not be mutually compatible, owing to both volumetric and structural constraints. It is not so much the complexity of the structure as the multiplicity of reordering routes which then leads to frustration in recrystallization. In network silicas, the options are so many, and their choice so stochiastic, that it is impossible to recover the original structure, short of global recrystallization from the molten state. In more compact ionic structures, fewer alternatives are available and with greater differentiation in free energy, but irradiation at low temperature can successfully preclude uniform adoption of the lowest energy medium-range ordered arrangement. Different metamict densities for different irradiation types or temperatures may reflect different proportions of the incompatible alternatives adopted.

\section{MODELLING THE METAMICT TRANSFORMATION OF SILICA}

Silica is known to adopt a wide variety of structures, most of which comprise threedimensional networks of corner-sharing tetrahedra with a silicon atom at their centers and oxygens as vertices [47]. Several of these networks are crystalline and distinct (cristobalite, tridymite, keatite, quartz and coesite -- in ascending order of density; see Table I, reproduced from our 1989 proposal with some additions and subsequent corrections). The crystalline polymorphs are all at least metastable at room temperature (through thermodynamically stable under formation over very different temperature ranges) and, once 
formed, cannot transform into any of the other forms without first melting. One of these, stishovite, a high-pressure form found in meteorite impacts, is actually close-packed ([SiO$\left.{ }_{6}\right]$ octahedra) and dense $\left(4.35 \mathrm{~g} / \mathrm{cm}^{3}\right)$. The others are all more open network structures based on the corner-shared $\left[\mathrm{SiO}_{4}\right]$ tetrahedral unit, with densities ranging from 2.26 to $3.01 \mathrm{~g} / \mathrm{cm}^{3}$. Coesite is also formed only in high pressure conditions; quartz and keatite form only hydrothermally. Cristobalite and tridymite can crystallize from the melt or in a devitrifying glass.

An indeterminate number of other $\mathrm{SiO}_{2}$ networks are glasses, or are at least aperiodic and lack the long-range translational periodicity required of crystalline solids. Silica is an easy glass former, as implied earlier, because the [4,2] connectivity in its network structure provides only as many constraints on each atom (or tetrahedron) as there are degrees of freedom; in other words, there is little structural redundancy to oppose arbitrary rearrangement of structure. $\mathrm{SiO}_{2}$ is thus delicately poised between a crystal and a glass. (Other oxides, like $\mathrm{B}_{2} \mathrm{O}_{3}$, have more freedoms than constraints and are seldom crystalline; $\mathrm{Al}_{2} \mathrm{O}_{3}$ has more constraints than freedoms and is rarely glassy -- an exception is a- $\mathrm{Al}_{2} \mathrm{O}_{3}$ corrosion films. Significantly, it is not possible to amorphize $\mathrm{GeO}_{2}$, isostructural with stishovite and having the [6,3] rutile structure, with electrons [48]). For this reason, silica may form not just one but many glass structures, limited only by the steric and topological constraints which are the subject of this section.

Several of these are identified also by their processing routes. Vitreous silica is formed by cooling the melt below its transition temperature and has a density about 2.2 $\mathrm{g} / \mathrm{cm}^{3}$. (This glass is sometimes called "fused quartz" because it can be produced by melting and recooling quartz, but the name is a misnomer for topological reasons discussed below.) Pressure-loading quartz produces a high-temperature glassy phase reported to represent a distinct structural variant [49], while irradiation of quartz produces a glass of unique density 
'TABLE I. Silica Polymorph Topology

\begin{tabular}{|c|c|c|c|c|}
\hline Polymorph & Stability Regime & Density & $\begin{array}{l}\text { Primitive } \\
\text { Ring Content }\end{array}$ & $N=3$ \\
\hline Stishovite & high pressure & 4.35 & (octahedra) & \\
\hline Coesite (site I) & high pressure & 3.01 & $\begin{array}{rl}2 & \text { 4-rings } \\
1 & \text { 6-ring } \\
2 & 8 \text {-rings } \\
10 & =\text { rings } \\
3 & 10 \text {-rings } \\
12 & 11 \text {-rings } \\
9 & 12 \text {-rings }\end{array}$ & 29 \\
\hline Coesite (site II) & & & $\begin{array}{cl}2 & \text { 4-rings } \\
2 & \text { 6-rings } \\
2 & 8 \text {-rings } \\
8 & 9 \text {-rings } \\
2 & 10 \text {-rings } \\
10 & 11-\text {-rings } \\
9 & 12-\text {-rings }\end{array}$ & 28 \\
\hline Quartz & $\begin{array}{l}\text { low temperature } \\
\left(537-870^{\circ} \mathrm{C}\right)\end{array}$ & 2.65 & $\begin{array}{c}6 \text { 6-rings } \\
40 \text { 8-rings }\end{array}$ & 30 \\
\hline Keatite (site I) & low temperature & 2.5 & $\begin{array}{ll}3 & 5 \text {-rings* } \\
5 & 7 \text {-rings } \\
3 & 8 \text {-rings }\end{array}$ & 28 \\
\hline Keatite (site II) & & & $\begin{array}{ll}4 & 5 \text {-rings } \\
4 & 7 \text {-rings } \\
4 & 8 \text {-rings }\end{array}$ & 30 \\
\hline Cristobalite & $\begin{array}{l}\text { high temperature } \\
\left(1470-1728^{\circ} \mathrm{C}\right)\end{array}$ & 2.32 & 12 6-rings & 24 \\
\hline Tridymite & $\begin{array}{l}\text { high temperature } \\
\left(870-1470^{\circ} \mathrm{C}\right)\end{array}$ & 2.26 & 12 6-rings & 25 \\
\hline Metamict & low temperature & 2.26 & $\overline{\mathrm{n}} \sim 6 ?$ & \\
\hline Vitreous & $\begin{array}{l}\text { high temperature } \\
\left(\mathrm{T}_{\mathrm{g}} \sim 1060^{\circ} \mathrm{C}\right)\end{array}$ & 2.21 & $\overline{\mathrm{n}}<6$ & \\
\hline
\end{tabular}

${ }^{*}$ Ring counts for Keatite are incomplete 
$\left(2.26 \mathrm{~g} / \mathrm{cm}^{3}\right)$ which is $14 \%$ less dense than quartz and $3 \%$ more dense than vitreous silica. Vitreous silica itself compacts under irradiation to this same unique density. Thus, at least two glassy states derived from different origins may have a common structure, and at least two glassy states must differ in structure because they differ in density.

While many oxides amorphize under heavy ion bombardment $[17,19]$, silicas are remarkable in their radiation response in that they undergo radiolysis $[8,50]$ and the product of that radiolysis is the metamict state rather than extended defect formation. These two features provide a unique opportunity to explore the metamict transformation atom-by-atom, since radiolysis invoives breaking bonds one at a time rather than inducing global disorder as in a collision cascade. Inui et al. [50] have, indeed, recently shown that, while radiolysis dominates the metamict transformation for electron irradiation at energies up to $1.5 \mathrm{MeV}$, even when ballistic damage becomes dominant at higher energies the transformation proceeds identically. While this susceptibility has unfortunate implications for the radiation stability of silicas, and silicates in general (such as nuclear waste storage glasses), the metamict response under simple bond breaking raises some profound questions about the structural options available to tetrahedral network structures, both crystalline and aperiodic, and in turn about the transformation pathways available between options. In one sense, these questions are both fundamentally about the structure of network glasses.

\subsection{The Metamict Transformation in Quartz}

We have for some time maintained that details of the metamict state, difficult to extract by diffraction techniques from fully amorphized material (see Section 4), can be guessed at from extrapolating observations of how it got to be. This is particularly true for silica because of the single displacements characteristic of radiolysis. Both high-resolution structure images (Fig. 1) and diffraction data (such as convergent beam patterns) obtained during radiolytic transformation of quartz on an electron beam $[29,48]$ have been shown to provide information on these intermediate pathways. We propose an extension of these approaches in quartz and other crystalline polymorphs, for which there was insufficient time or money in the last funding period, in Section 4.3. A second approach which we have pursued is the computer modelling of the early stages of structural rearrangement occurring 
during radiolytic amorphization.

Radiolysis of quartz involves excitonic rupturing of an Si-O bond to form an oxygen vacancy (the well-known $E^{\prime}$ center) and its complementary defect, the peroxy radical [8,51]. The mobility of these defects are enhanced in the presence of an irradiation field because they will be rendered in excited states; with this enhanced mobility it is possible for several oxygen atoms to rebond, so as to bridge two silicon atoms, one of which is different from that bonded originally. The process results in a different arrangement of $\left[\mathrm{SiO}_{4}\right]$ tetrahedra, giving eventual rise to a small amorphous region within the crystal which will grow in size as more Si-O bonds break and are rebonded in different stochastic ways. In the equilibrium state, the atoms surrounding the distorted region will relax so that the elastic energy is minimized. For small displacements of atoms from their equilibrium positions, we can suppose the total energy to be proportional to the sum of the squares of these displacements. Therefore, in the minimum energy configuration, the sum of the squares of the displacements will also be minimum. While this approach has little of the sophistication of a molecular dynamics simulation, it is considerably simpler to implement for the welldefined configurations involved and does not require explicit knowledge of Si-O, O-O and Si-O potentials. An abbreviated account of initial results has been published [52] and is supplemented here by some later results and more detail.

In the present work we have built a simple engineering model simulating the process described above. The program is written in VAX Fortran and operates under the VAX/VMS operating system on our (now somewhat outdated) VAX Station II computer purchased 1n 1985 with DOE funds. We have used clusters of two sizes in our program: 27 unit cells (273 atoms) and 64 unit cells (628 atoms); the limit to the size of the cluster is essentially dependent on the computer memory available. The orthogonal coordinates of the atoms in the cluster are calculated by program CRYSTAL. Program PLOT plots and displays the crystal structure on the screen, a hard copy of which can be obtained on the printer. There is a choice of bonds to be drawn: Si-O, Si-Si or O-O. The coordinates of any atom or the distance between any two atoms can be displayed. PLOT uses features from NAMROD (Nagoya University Molecular Structure Display Program [53]) to draw perspective diagrams of molecules representing atoms and bonds as balls and sticks re- 
spectively. The orthogonal coordinates of the atoms and the interatomic distances are stored in a file.

We have used program DLS-76 [54] to minimize the sum of the weighted squares of the deviations from equilibrium interatomic distances. We have prescribed these interatomic distances to be $0.162 \mathrm{~nm}$ for Si-O, $0.2645 \mathrm{~nm}$ for $0-0$ and $0.309 \mathrm{~nm}$ for Si-Si bonds with weights in the ratios 2:1:0.1 and in some cases $2: 1: 1$ for the sake of comparison. These weights are chosen so as to maintain the tetrahedral structure while giving maximum flexibility to the angles between tetrahedra. The resulting crystal structure with the atoms in the relaxed positions is displayed by PLOT.

Fig. 2(a) shows a cluste of 273 atoms (27 unit cells, or 3 cells each in $x, y$ and $z$ directions) in a perfect crystal. Fig. 2(b) is the same cluster with the crystal disrupted in the center so that the connectivity of the tetrahedra is changed. We did this by breaking two existing Si-O bonds and replacing them with two new ones. Fig. 2(c) plots the atoms of Fig. 2(b) after they are relaxed. The coordinates of some of the outer $\mathrm{Si}$ atoms in the cluster were kept invariant for reasons of stability and also because we have assumed that the strained region is confined within the cluster and does not extend beyond it. We find that the average $\mathrm{Si}-\mathrm{O}$ distance in the strained region is increased by $2.5 \%$, the $\mathrm{O}-\mathrm{O}$ distance by $4 \%$ and the $\mathrm{Si}-\mathrm{Si}$ distance by $3 \%$. These are reasonable values, since quartz expands $14 \%$ by volume in its metamict transition, corresponting to an increase of about $4-5 \%$ in length. We also notice that the crystal structure surrounding the strained region is overly distorted from a perfect lattice configuration. As mentioned above, we kept the coordinates of the Si atoms at the outer edges of the cluster invariant, and this has resulted in some large bond distortions because the cluster is clearly not big enough to accommodate the strain. We took care of this by removing the constraints on two corner Si atoms. The problem did not occur when we used the larger cluster described next.

Figures 3(a-c) are similar plots for a cluster of 64 unit cells (4 unit cells each in $\mathrm{x}$, $y$ and $z$ direction) consisting of 628 atoms with a similar rearrangement of tetrahedra. The weights for Si-O, O-O and $\mathrm{Si}-\mathrm{Si}$ distances are, in this case, in the ratio 2:1:1. The coordinates of all the Si atoms along the outer edges of the cluster were kept invariant. We find a similar increase in Si-Si, Si-O and O-O distances. The crystal structure surrounding 
the strained region is also similarly distorted.

Figures 4 and 5 all plot clusters of 27 unit cells. Fig. 4(a) plots a different rearrangement of the tetrahedra, Fig. 4(b) the result after the atonis were relaxed. The interatomic distances are about the same as in Fig. 4(b) which is what we expested. Fig. 5(a) has one tetrahedron removed from the center (equivalent to removing one Si and two oxygen atoms), with Fig. 5(b) showing the result after the atoms cure relaxed. Since we have decreased the number of atoms we expect a larger increase in bond lengths. That is, indeed, what we find. The Si-O distances are increased by about $4 \%$ whersas O-O and Ji-Ji removed. The bond distortions are about the same as in Figs. 5(a,b). The weights for Si-O, O-O and Si-Si distances are in the ratio 2:1:1 for Figs. 4(b) and 5(d).

The present work illustrates the feasibility of modelling strain centers in irradiated quartz by minimizing the square of the displacements of the atoms from their equilibrium positions. The bond distortions are calculated to a fairly reasonable accuracy. With the meinory available in our present system, it was nut possible to do computations with clusters larger than 64 unit cells. Since DLS-76 uses a matrix inversion routine, the cpu time is increased considerably with increasing size of the cluster. In fact, the time for one iteration for 64 cells was 10 hours cpu time. We are working on changing the matrix inversion routine in DLS-76 to make it faster.

With larger clusters, it is possible to extend the damaged region by repeating the process of rearranging the tetrahedra; for example, we could combine the arrangements shown in Figs. 2(b) and 3(b). One could also create two strained regions separately in the same cluster which, predictably, would disrupt the surrounding crystal considerably. Such combinations could be guided by our knowledge of the combinatorial geometric possibilities for rearrangement discussed below.

\subsection{Combinatorial Geometry of Aperiodic Silica}

The classical description of crystals is couched in the languages of symmetry and periodicity. Indeed, a complete description of a crystal (in terms of its atomic coordinates) can be arrived at using these two languages and a knowledge of its constituents, even though 


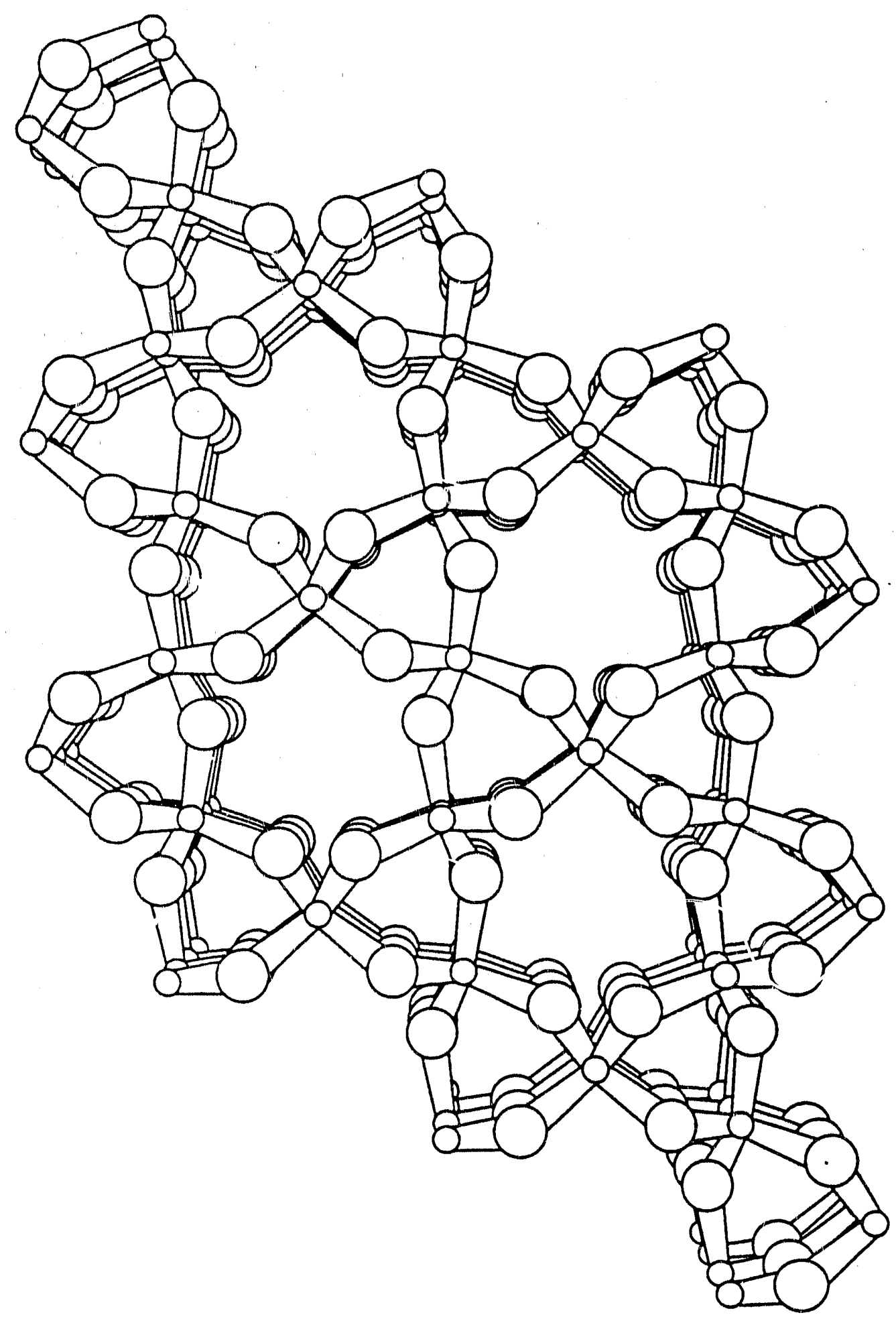

Fig. 2(a) Representation of 27 unit cells of quartz with no defects. 


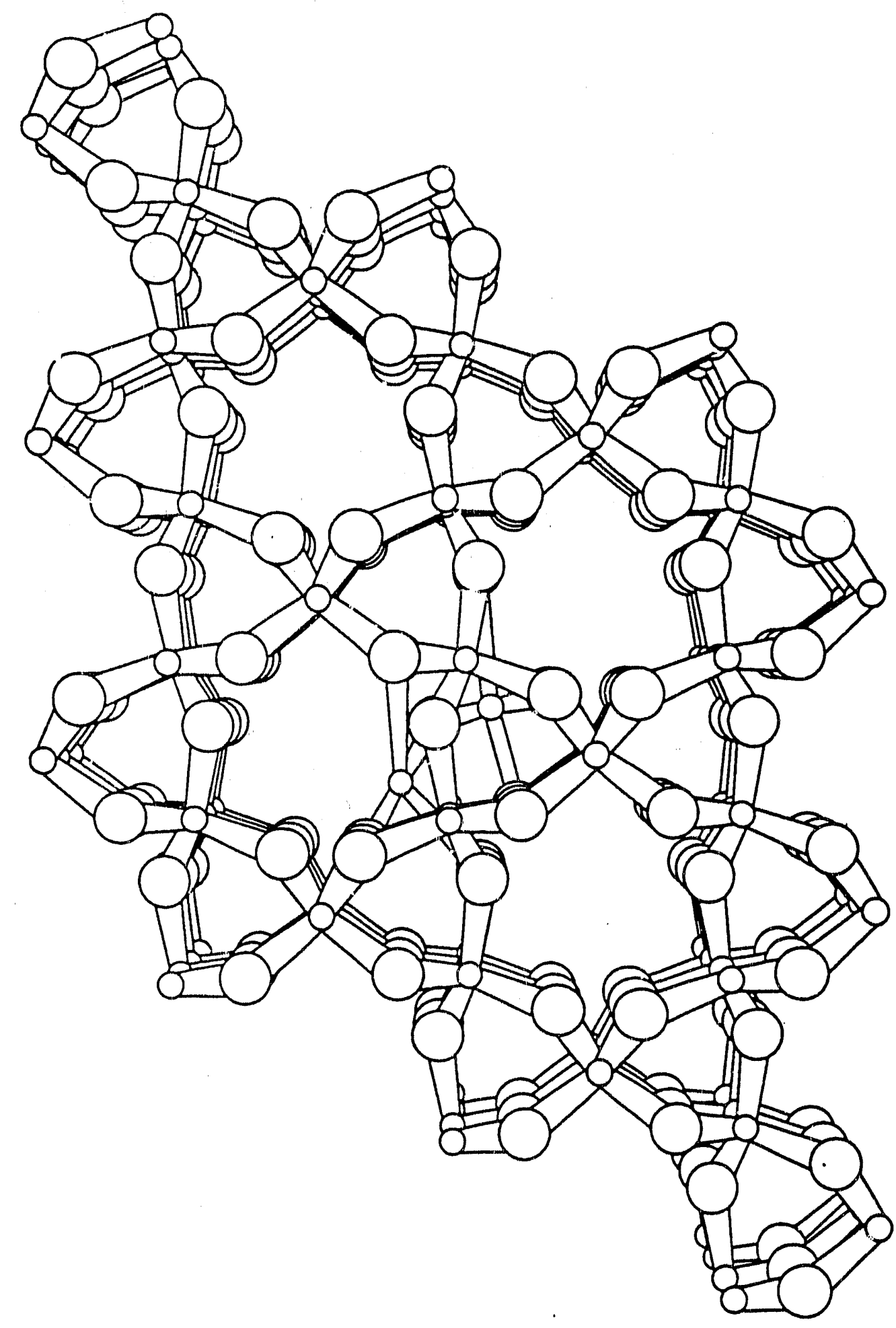

Fig. 2(b) Representation of 27 unit cells of quartz with 2 central tetrahedra rebonded. 


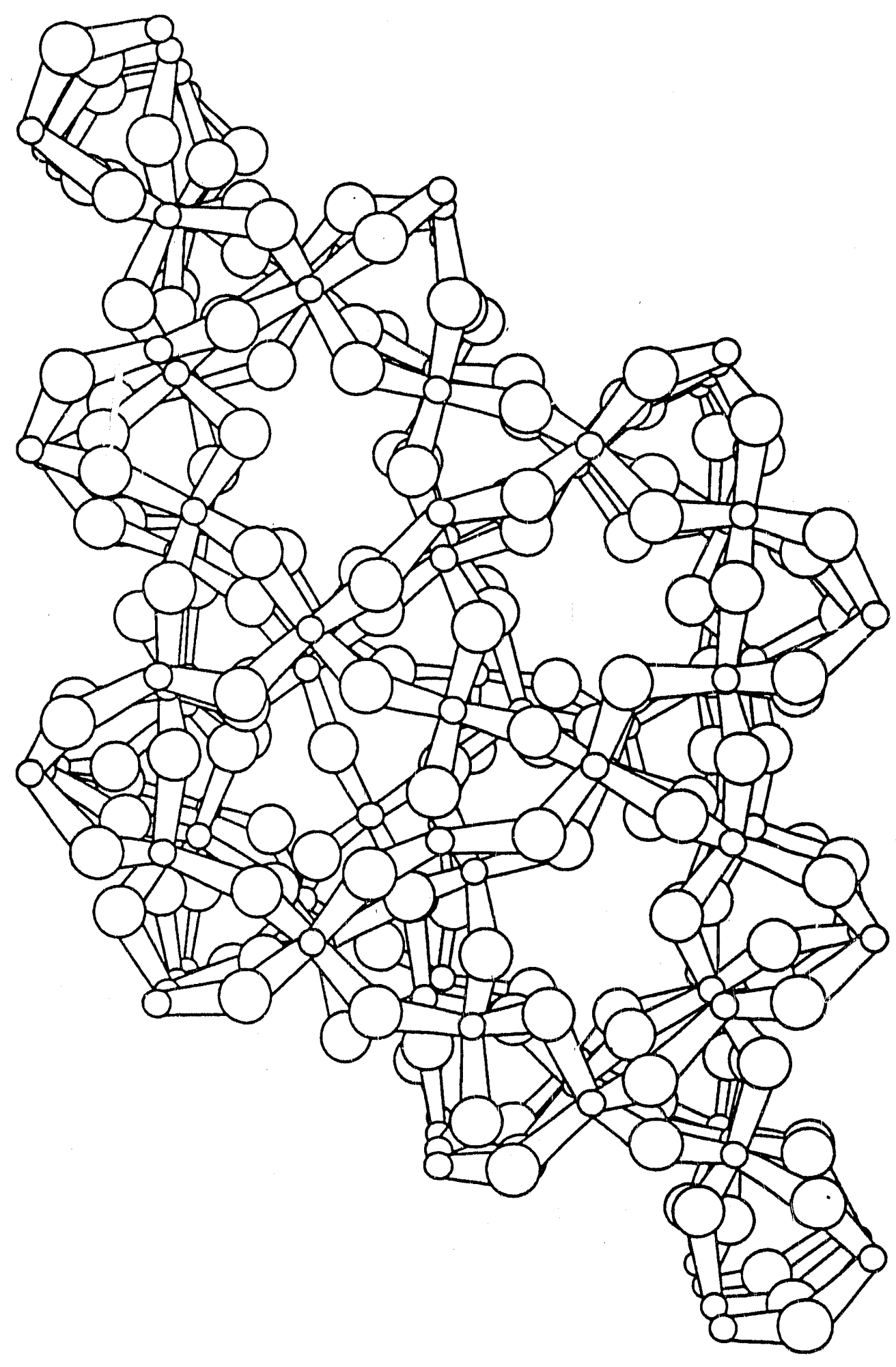

Fig. 2(c) Representation of 27 unit c ells of quartz with 2 tetrahedra rebonded and the structure relaxed. 


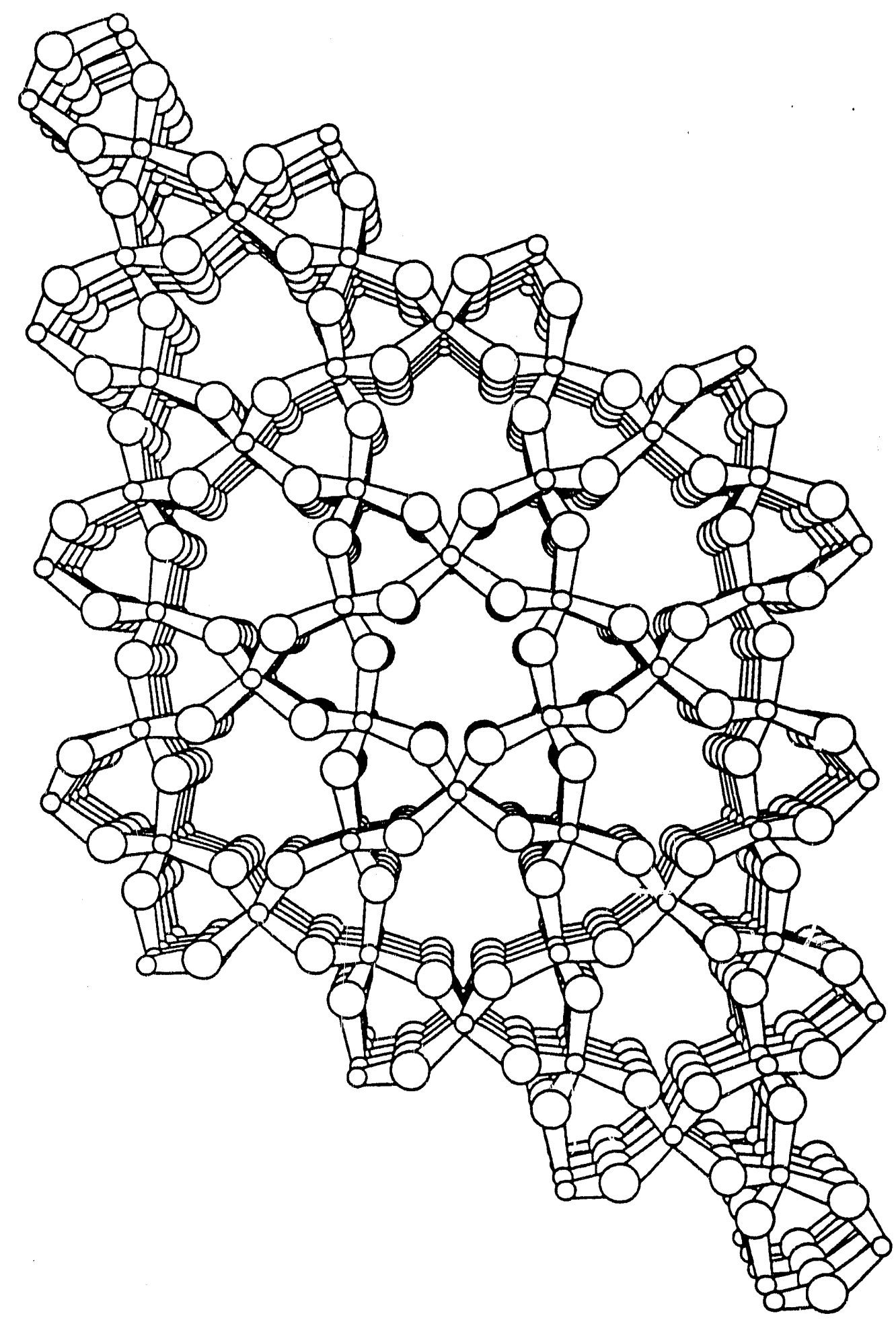

Fig. 3(a) Representation of 64 unit cells of quartz with no defects. 


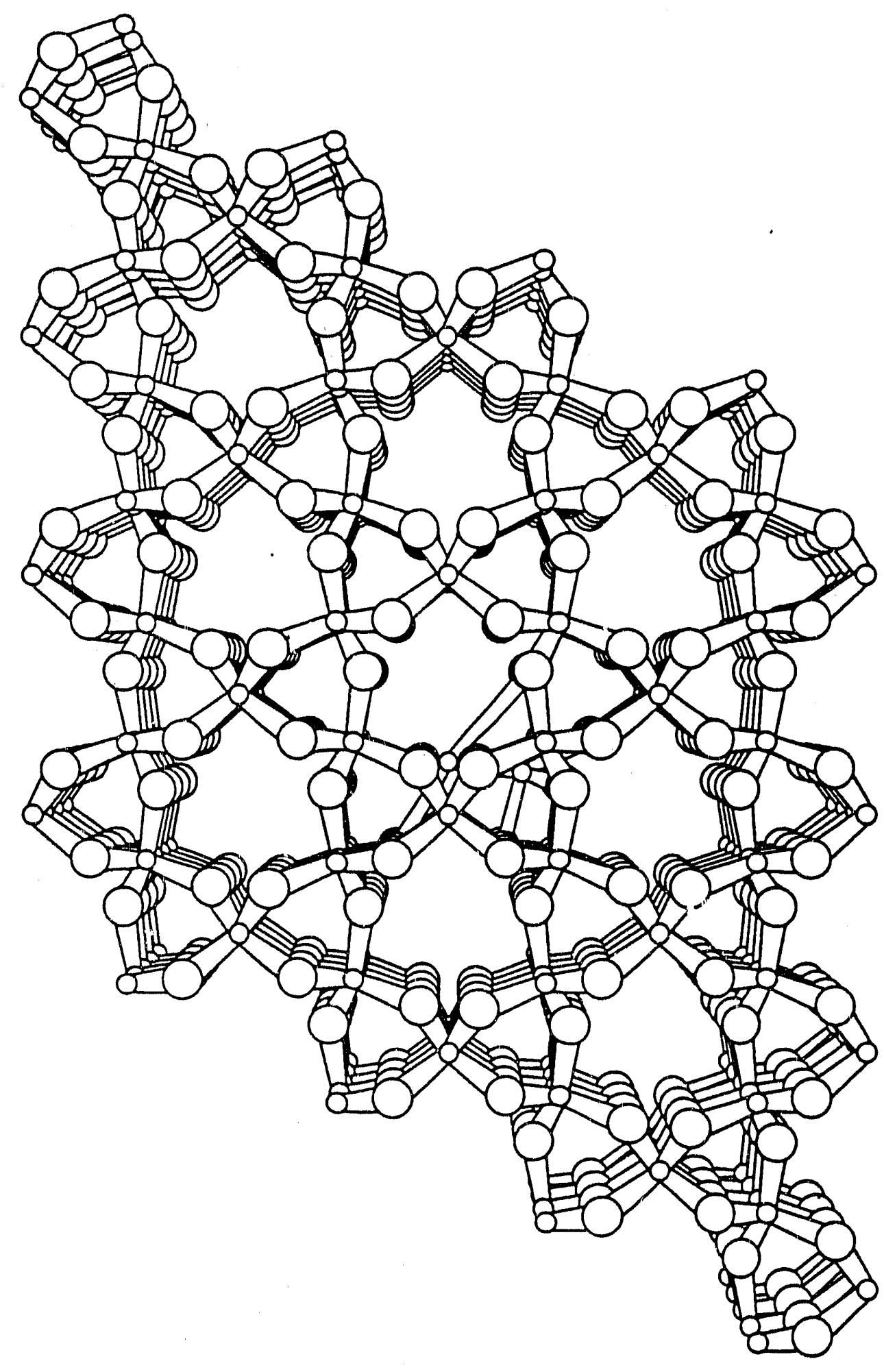

Fig. 3(b) Representation of 64 unit cells of quartz with 2 central tetrahedra rebonded. 


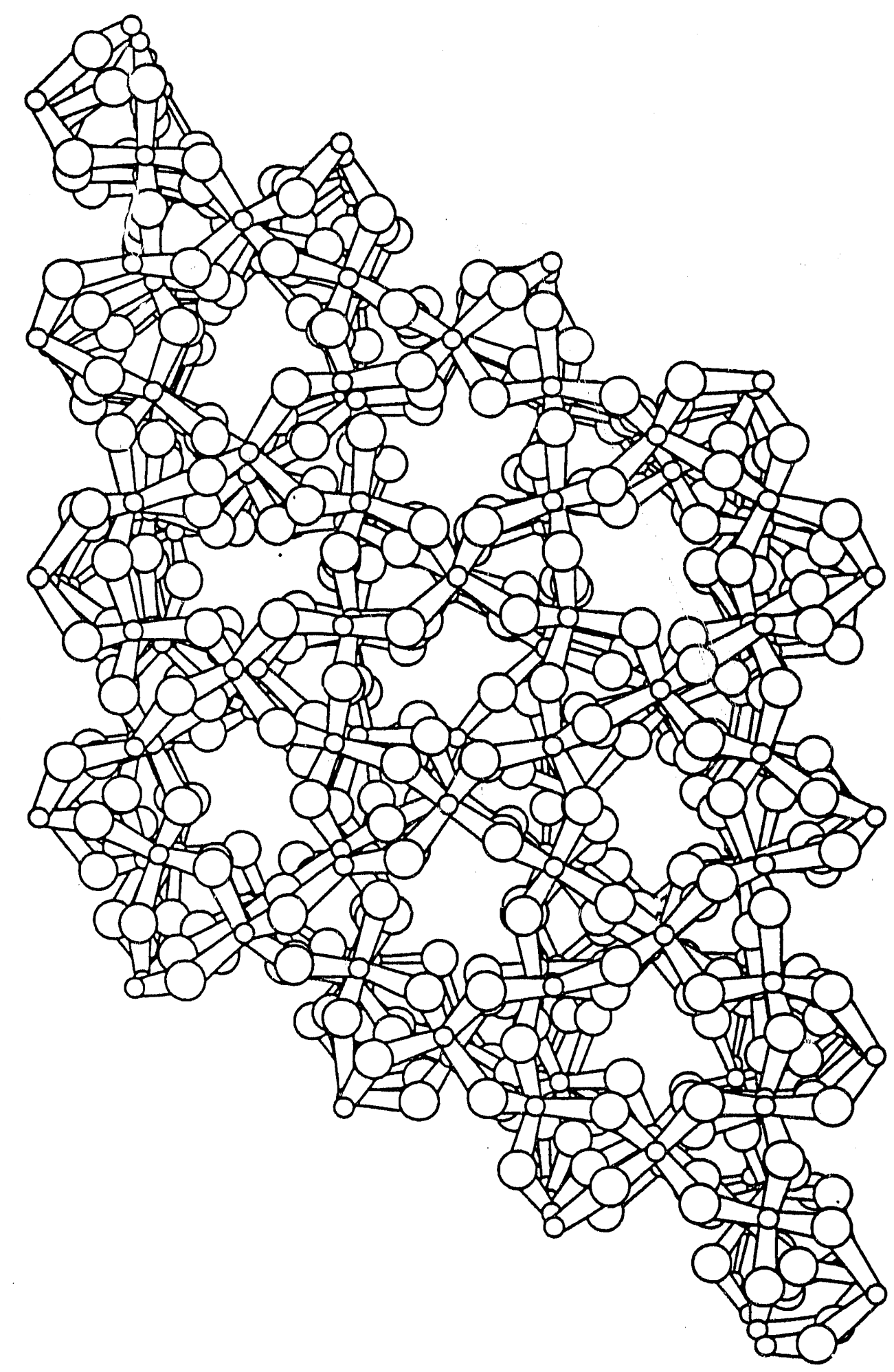

Fig. 3(c) Representation of 64 unit cells of quartz with 2 tetrahedra rebonded and the structure relaxed. 


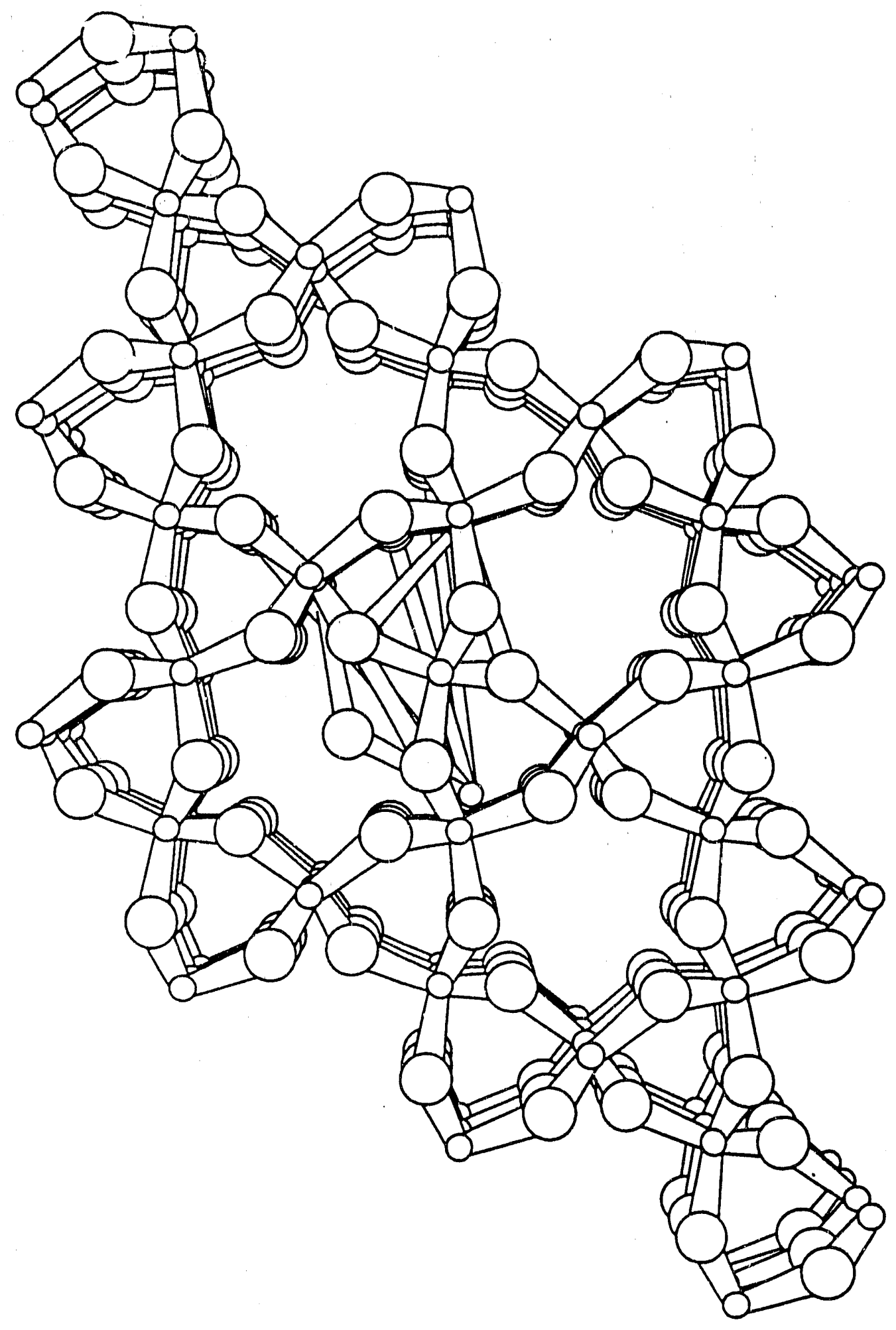

Fig. 4(a) Representation of 27 unit cells of quartz with 4 central tetrahedra rebonded. 


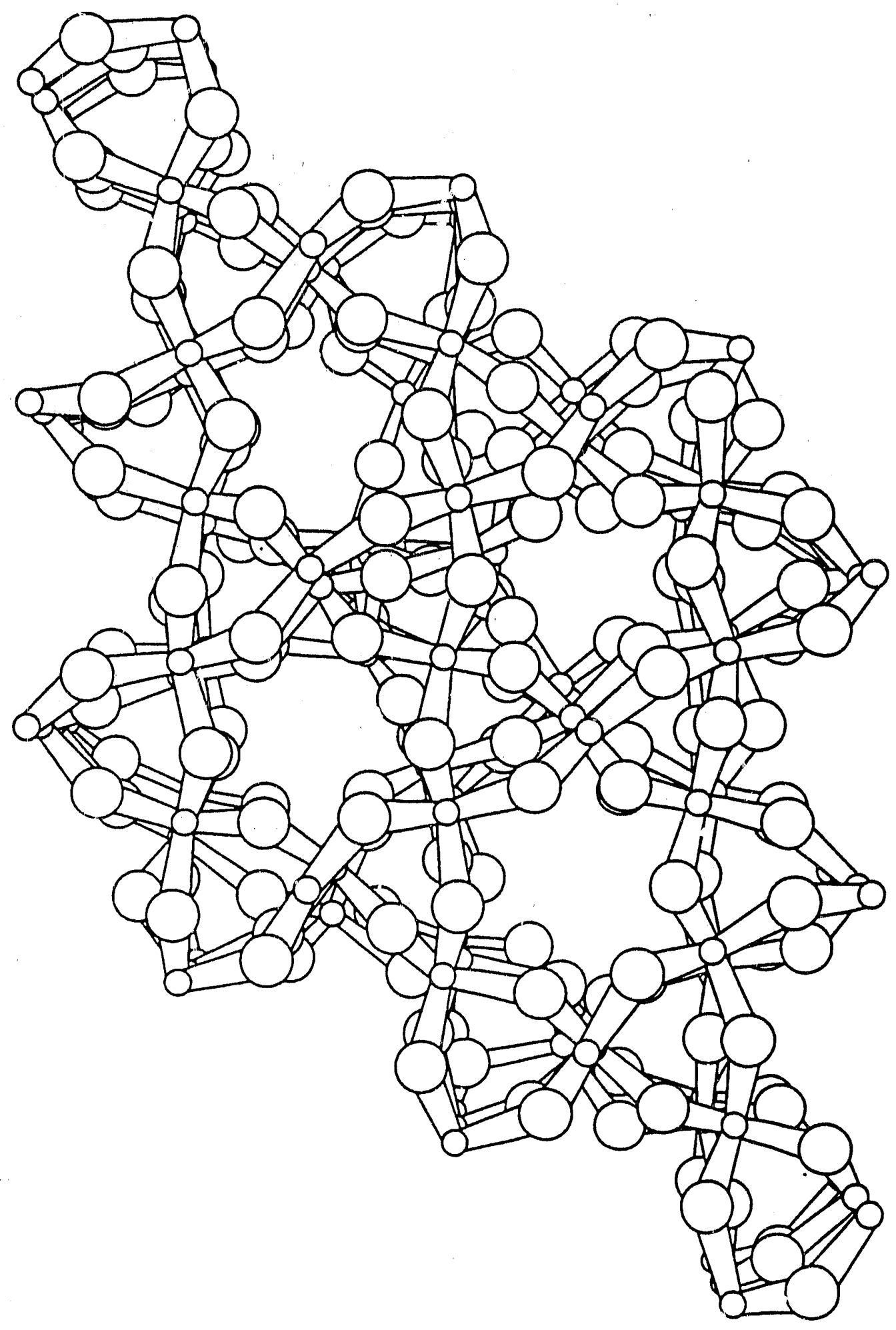

Fig. 4(b) Representation of 27 unit cells of quartz with 4 tetrahedra rebonded and the structure relaxed. 


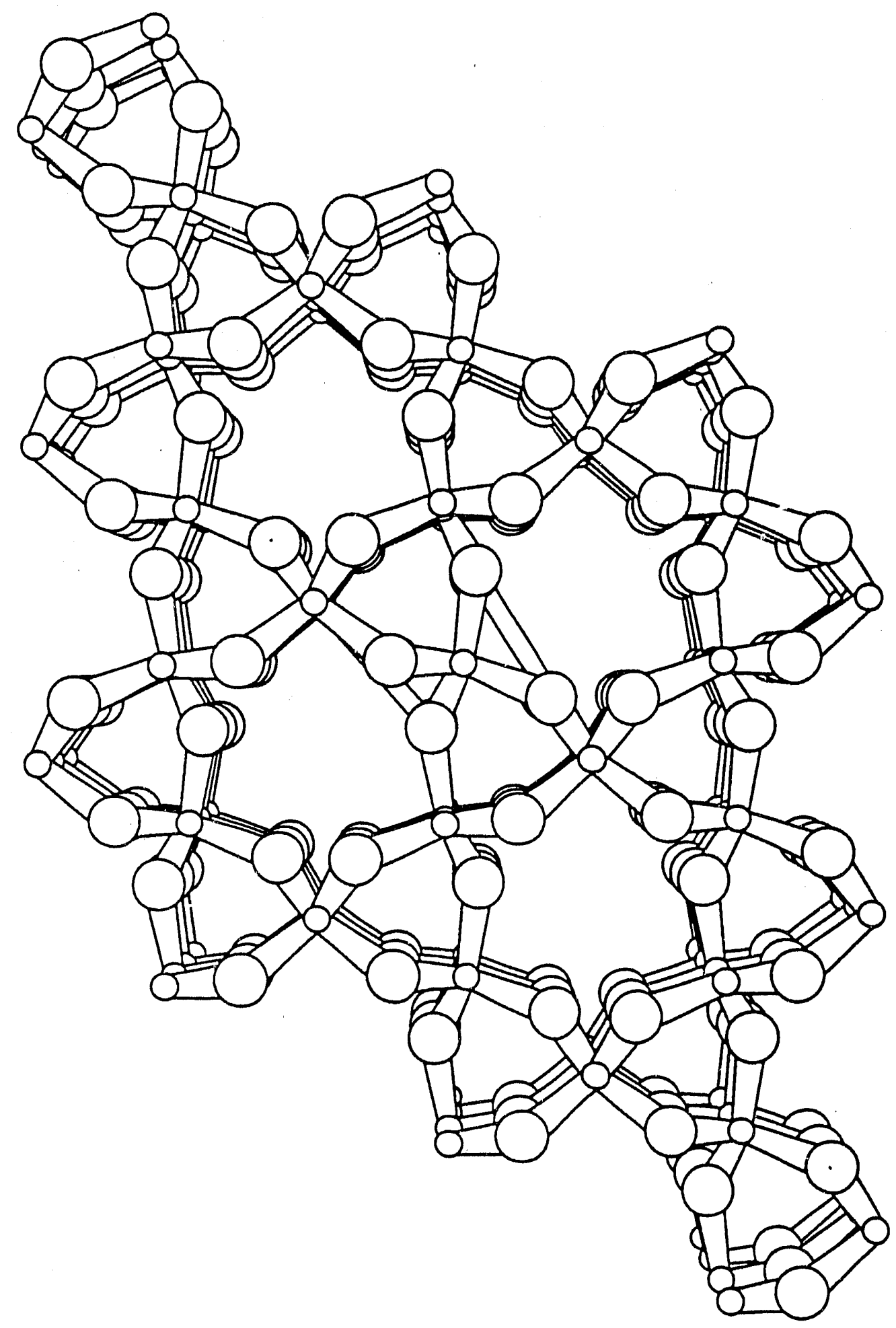

Fig. 5(a) Representation of 27 unit cells of quartz with 1 tetrahedron removed. 


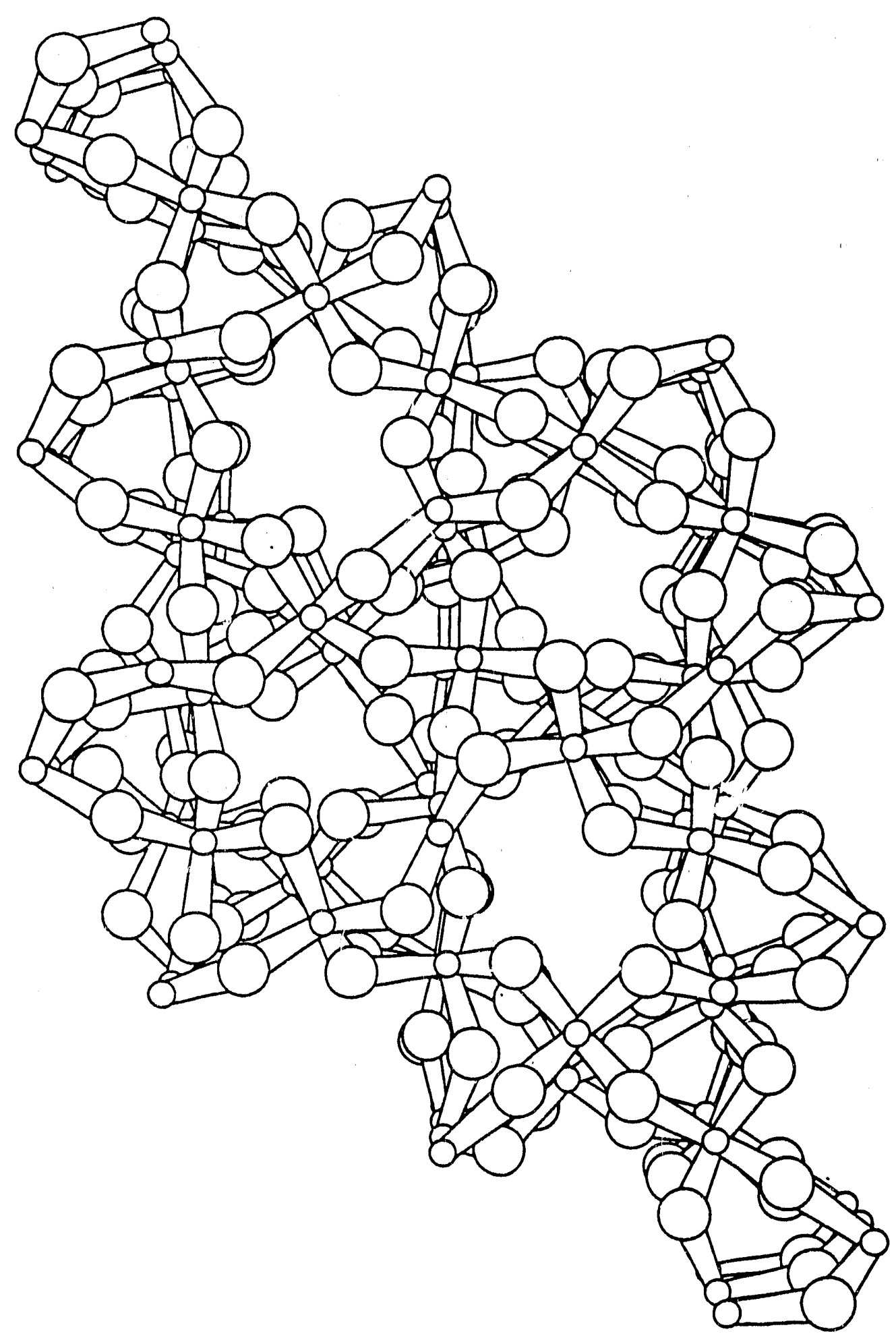

Fig. 5(b) Representation of 27 unit cells of quartz with one tetrahedron removed and the structure relaxed. 


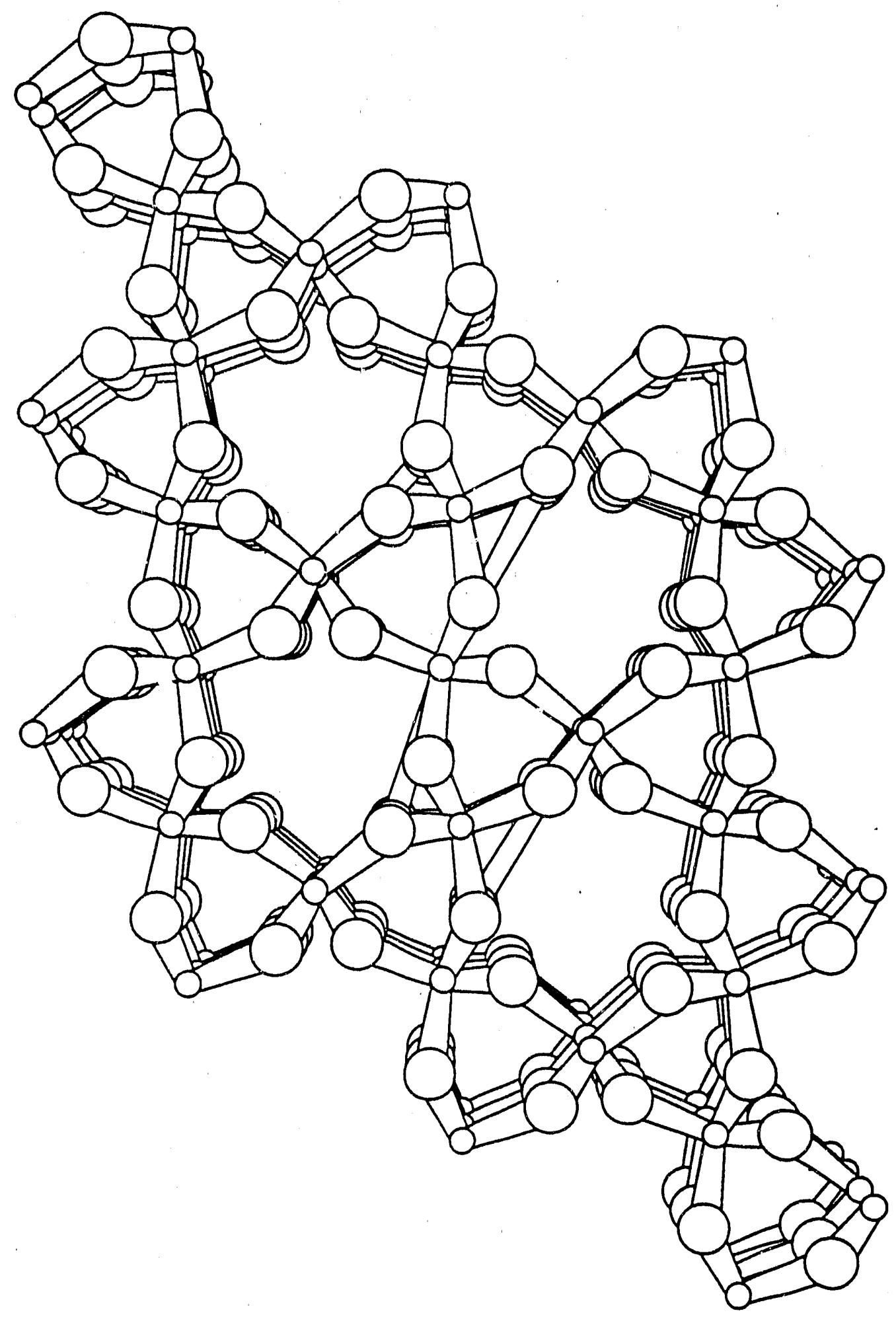

Fig. 5(c) Representation of 27 unit cells of quartz with 2 tetrahedra removed. 




Fig. 5(d) Representation of 27 unit cells of quartz with two tetrahedra removed and the structure relaxed. 
there is little in either language which reflects in a direct way the local environment about any atom. Glasses are neither symmetric nor periodic, but neither are they random, and it is the similarity in local environment with that of the crystalline analogues which conveys similar physical and classical properties. What crystals and glasses also have in common is topology, and a topological description is possible for both which reflects even more of the structural commonality. Using network silica as the model system, we have been able to distinguish completely each of the crystalline network silica polymorphs on the basis of its local topology [55], as detailed in our 1989 proposal, and have now applied insights derived from this exercise to an investigation of the structural possibilities for fully-connected silica glass structures [56], which suggest a new model for the intermediate- and long-range order of vitreous and amorphized silicas [57].

The crystalline nature of quartz was first established in mineralogical investigations of crystal growth facets in the late 19th-century, and details of the atomic structure in both high- and low-temperature distortions worked out by X-ray diffraction in 1920's. An appreciation of the network linkage of $\left[\mathrm{SiO}_{4}\right]$ coordination polyhedra in this and other crystalline silica pclymorphs deriving from such diffraction studies led Zachariasen [58] to postulate the notion of a continuous random network (CRN) as the corresponding structural basis for oxide (including silica) glasses. The important features of the model are that, unlike for crystals, there are no fixed Si-O-Si bond angles and no fixed interatomic distances beyond first-neighbor atoms. Despite the fact that the model was then (and has since been) depicted only in two dimensions, and has never been proved to be infinitely extendable, the CRN model has gained not only currency but ascendancy. The first model for vitreous silica to be put forward was, however, the crystallite model of Lebedev [59] which has continued to exert its fascination in the form of subsequent models of glassy silica as a mix of crystalline polymorphs [60] or as paracrystalline distortions based on rotational freedoms [61] or siliconyl $\left(\mathrm{O}=\mathrm{SiO}_{2}\right)$ structural groups [62].

Cooper [40] has pointed out that the basis for Zachariasen's structural rules for glass formation is topological, in that what is characteristic is not the structural unit themselves but the way in which they are connected together -- their combinatorial geometry. The notion of a topological network as an analogue of the crystalline lattice has been 
subsequently explored by Wright et al. [63,64]. Meanwhile, crystalline forms continue to be described in terms of periodic repetition of symmetry elements or of space-filling by periodic repetition of regular polytopes. That this way of describing crystalline structure has so dominated thinking is due to an accident of mineralogical history and the aesthetic of periodicity. There is no reason why crystalline network structures should not be described with the same topological formalism applied to non-crystalline nets, and indeed there is considerable advantage in doing so because the approach reveals the commonality of local structure shared by crystalline and non-crystalline arrangements.

We first briefly describe a method for enumerating the combinatorial possibilities for fully-connected tetrahedral network structures, as exemplified by $\mathrm{SiO}_{2}$ crystalline polymorphs, and for establishing the limitations of these possibilities which are ultimately more topological than steric. The possibilities and limitations function in the same way as the rules of crystallography do for crystals: they provide a vehicle for usefully describing the structure, they categorize structural types into classes, and they provide predictive power for extrapolating to unknown or uncharacteristic structures. The focus is on the one common unit of structure, an $\left[\mathrm{SiO}_{4}\right]$ tetrahedron, and how it is connected to its first, second, third, fourth, and so on, neighbors in network. Even at second network neighbors, few structural differences emerge: cristobalite, tridymite, keatite and quartz all have twelve second network-neighbors, though coesite has only ten. This is why it is so difficult to extract information about structural differences for glasses from diffraction or EXAFS data which emphasize shorter-range correlations. It is only at third network-neighbors, $(\mathrm{N}=3$, Table I), where 6-rings close, that the topology of the crystalline polymorphs significantly differs: cristobalite has 24 , tridymite 25 , quartz 30 , keatite 28 or 30 , and coesite 28 or 29 (the latter two polymorphs have two topologically inequivalent tetrahedron sites). This focus on connectivity also provides the means to quantify reconstructive phase transformations; for example, the transformation between cristobalite ( 24 third network-neighbors) and quartz (30 third network-neighbors) must involve creation or elimination of six tetrahedra, which explains why this transformation does not occur.

Connectivity can be characterized, uniquely for the crystalline polymorphs and at least generically for network glasses, by a set of rings, or closed paths, of connected 
tetrahedra which pass through a tetrahedron of interest. The rings that are of interest are those which are indecomposable, that is, which cannot be expressed as the sum of two or more smaller rings; these rings we call primitive rings, and the (surprisingly finite) set of all primitive rings passing through a given tetrahedron we call the local cluster.

That rings form at all is a necessary consequence of steric hindrance; an ever branching tree increases in density without limit (unless its structural units get progressively smaller, as they do in self-similar fractal constructions), unless the branches somewhere close back on themselves. Rings serve as perfectly adequate descriptors of two-dimensional networks because the areas they enclose tessellate (tile completely) two-dimensional space; indeed, the Zachariasen model is always seen depicted in two dimensions because the topological choices are trivial: every $\left[\mathrm{SiO}_{3}\right]$ triangle must have three primitive rings passing through it and these must average by Euler's theorem to 6-fold rings [65]. Generalization to three dimensions is not permissible, however, because three-dimensional space can be tessellated only by three-dimensional void polytopes [66], the faces of which are not uniquely described by rings. A tetrahedron, having six edges, can close multiple rings, whereas a trianlge in two dimensions closes only three. Ring statistics are necessarily incomplete descriptors of structure in three dimensions.

The primitive ring content of the local cluster is, nevertheless, remarkably descriptive, and each of the crystalline network polymorphs is distinguishable on this basis (Table I). For example, a local cluster of quartz contains six 6-rings and forty 8-rings; cristobalite has twelve 6-rings passing through each tetrahedron, while tridymite also has twelve 6-rings, only eleven of which are linearly independent. Two inequivalent tetrahedron sites exist for both keatite and coesite, each with different primitive ring content.

One interesting property to emerge from such considerations is the relationship between primitive ring size and density. Whereas it might be supposed that the presence of large rings implies lower density, in fact the opposite holds true, as shown in Table I. This result o'tains because large rings can fold back on themselves, whereas small rings cannot. Also, the presence of odd-numbered rings in crystalline networks (e.g. 5- and 7-rings in keatite, 9- and 11-rings in coesite) contradicts the traditional association of oddmembered rings with glassy structures. From the position of vitreous silica in the density 
table, it is reasonable to deduce that the average primitive ring size is near six and that the average number of 6-rings is probably close to twelve, as in the two crystalline polymorphs, cristobalite and tridymite, of similar density. (The constraints on structures with 6-rings are discussed below). The fact that vitreous silica densifies to form metamict silica suggests that some increase in primitive ring size has occurred.

Physical modelling has played a large part in the approach to be describer for aperiodic structures and has led us to intuitive truths which were later supplied their mathematical proofs. The model of vitreous silica by Evans and Shirley King [67] was among the first to attempt to depict the random network in three dimensions, and it was their models that provided King [68] with information about the ring structures of crystobalite and tridymite and exposed the utility of enumerating rings passing through a given center in aperiodic networks. Our models were generated using transparent plastic tetrahedra, $50 \mathrm{~mm}$ on a side, folded up from acetate sheets and connected together with pipe cleaner segments.

The object of our model building exercise was, however, quite different. While Evans and King, Bell and Dean [69] and all subsequent modelers, including Gladden's recent computer building algorithm [70], have attempted to generate models which conformed to experimentally-established bond and dihedral angle distributions or imposed steric constraints, our intent was solely to explore the range of combinatorial possibilities for tetrahedral network structures and to discover the limits imposed by topological constraints [57]. It was therefore possible to construct large models quickly and so produce numerous examples from which to distinguish small difference between them.

Initially, models of glass structures were built which incorporated a desired local structure. For example, models were constructed to fourth network neighbors of "quartzlike" and "cristobalite-like" glass which have a local cluster at each tetrahedron which approximates either that of quartz (six 6-rings, forty 8-rirgs) or of cristobalite (twelve 6rings). To enumerate the primitive ring content, the tetrahedron connections (vertices, appropriately numbered) were read into a Symbolics computer (made available through MIT's Artificial Intelligence Laboratory) for which appropriate LISP code has been written for finding primitive rings. The models so constructed were completely differentiable, 
proving that two glasses with readily distinguishable network topologies are distinct from each other and can have different properties. These structures are nevertheless not unique in that there may exist many, e.g. quartz-like glasses, which are distinct phases but differ little from each other in network topology.

A crucial question arising in these studies is whether a repeat unit can exist in a glass in the sense that if a local environment (viz the local cluster) is associated with one tetrahedron, can that same local environment be repeated at every tetrahedron? It is, for example, possible to repeat a local cluster comprising twelve primitive 6-rings, because that is the case for the crystalline networks of cristobalite and tridymite. Local clusters of fourteen, fifteen and even sixteen 6-rings are constructable without steric difficulties, and can even be embedded in a network, but cannot be repeated at every tetrahedron. We have, in fact, shown [71] that a cluster with more than twelve linearly-independent 6-rings cannot be propogated. A structure with fewer than twelve 6-rings (and no larger rings) is pathologically an underconnected "tree" and soon overgrows itself, resulting in steric problems and unacceptable densities. There is therefore something generic about twelve 6-rings, and the starting point of our most recent model lies in the characterization of a fully-bonded infinite silica network whose primitive rings are 6-rings. Some experimental support for models of this type is provided by Konnert and Karle [72].

Both cristobalite and tridymite, two high temperature silica polymorphs, contain twelve such rings, and both the correlation between density and ring size and that between formation temperature and ring size distribution argue for vitreous silica (the thermal glass) having a similar ring content. Cristobalite and tridymite differ only in the stacking sequence of sheets of tetrahedra, $A B C$ for cubic (c) cristobalite and $A B$ for hexagonal (h) tridymite. The linkages between adjacent sheets are made using 6-rings. A silica network, fully bonded and composed entirely of primitive 6-rings can readily be shown to be a one-dimensional crystal, as outlined below. Indeed, many models were constructed by Dr. Marians in a vain attempt to build a three-dimensional network with only 6-rings and no periodicity in any direction.

The claim follows from three theorems whose proofs have been given by Marians and Burdett [57] The first is that, in a network of tetrahedra whose primitive rings are all 6- 
rings, each tetrahedron has at least one face which is part of a two-dimensional 6-ring subnetwork of alternating tetrahedra, as shown in Fig. 6. A two-dimensional subnetwork contains only vertices, edges and triangles [71]. Such a subnetwork occurs as the basal plane of tridymite and $\{111\}$ planes in cristobalite. The tetrahedra in these planes alternate pointing up and down, as claimed, but the result is quite general. All the faces of a tetrahedron in cristobalite are part of such a subnetwork, but only one face of a tetrahedron in tridymite. The second theorem asserts that in a three-dimensional network where irreducible rings are 6-rings, each tetrahedron has exactly twelve 6-rings, two through each of its edges. The sterically viable arrangements of these twelve 6-rings exhibit only four possible local clusters which are embeddable in a 6-ring infinite network. These are shown in Fig. 7 and correspond to cristobalite-like and tridymite-like stacking sequences which may repeat in arbitrary sequences, such as hhcchc, not unlike polytypic stacking sequences in $\mathrm{SiC}$ [73]. It follows, from a third theorem, that once either a cristobalite-like layer or a tridymite-like layer has formed, then the rest of that layer must form similarly. A silica network composed entirely of primitive 6-rings must therefore be topologically, at the very least, a "one-dimensional" network crystal with a unique direction normal to the twodimensional subnetwork. A three-dimensional network cannot be constructed with only 6rings and no periodicity in any directions.

One model of silica glass structure to emerge from these observations is one in which discrete domains ("blobs") of such "almost" crystalline material " composed wholly of 6-rings, are linked together by interfacial materials ("glue") exhibiting other ring sizes. The interfacial material must necessarily consist of a mixture of both larger and smaller rings. Our models invariably had interfacial material comprising mostly 8-rings, but also of some rings smaller than 6-rings. Reference to Table I reveals that a "glue" containing predominantly 8-rings (quartz-like) leads to the densities unacceptably high for vitreous silica. Vitreous silica must therefore contain some rings smaller than 6-rings. 5-rings are likely, and in fact a similar conclusion has been reached recently by Gladden [70] using a structure building algorithm. A two-dimensional analogue is illustrated in Fig. 8.

The modulated network model suggested here retains features of both the random network and microcrystallite models. It differs from the continuous random network model 


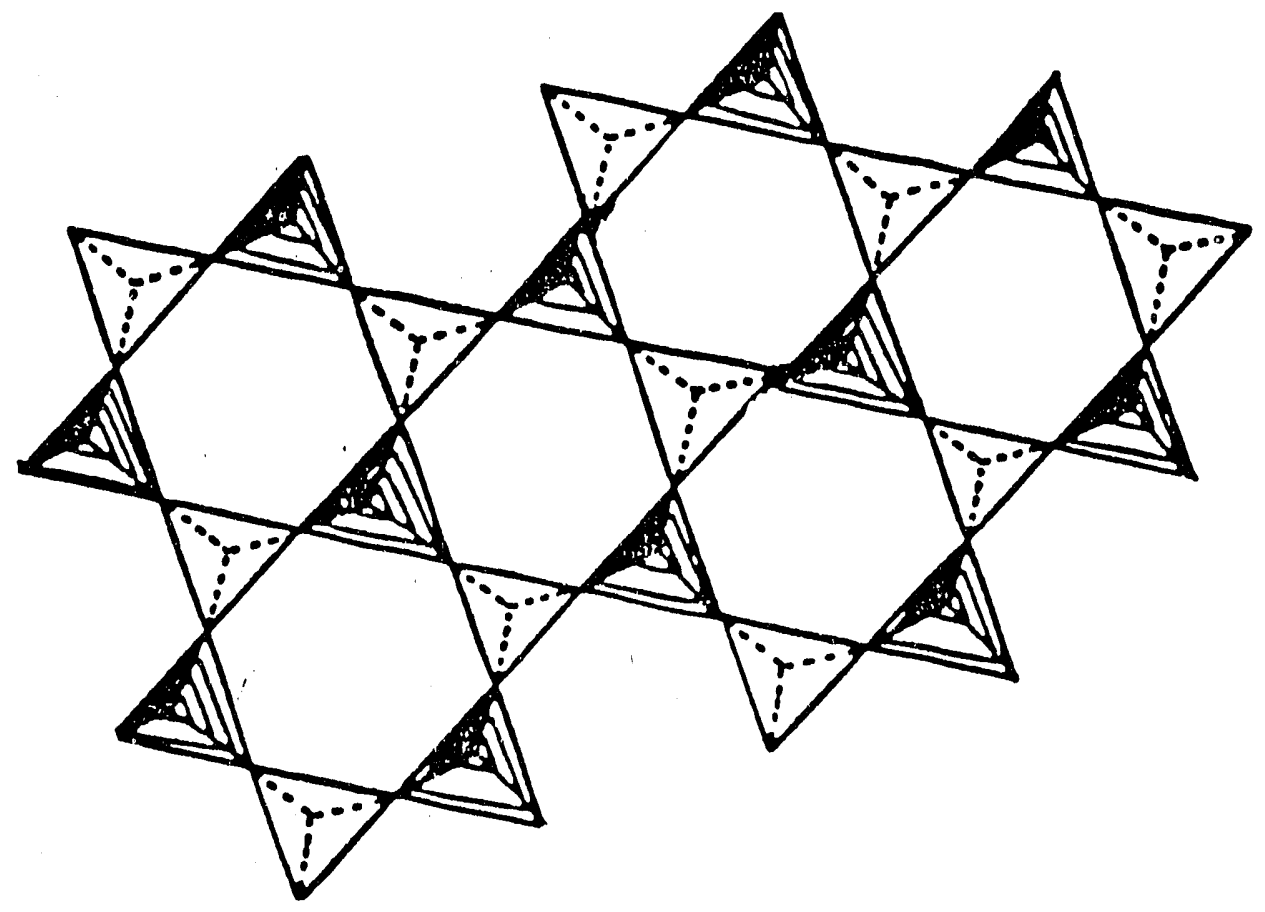

Fig. 6 6-ring subnetwork of alternating tetrahedra as found on the basal plane of tridymite and on $\{111\}$ planes of cristobalite. 

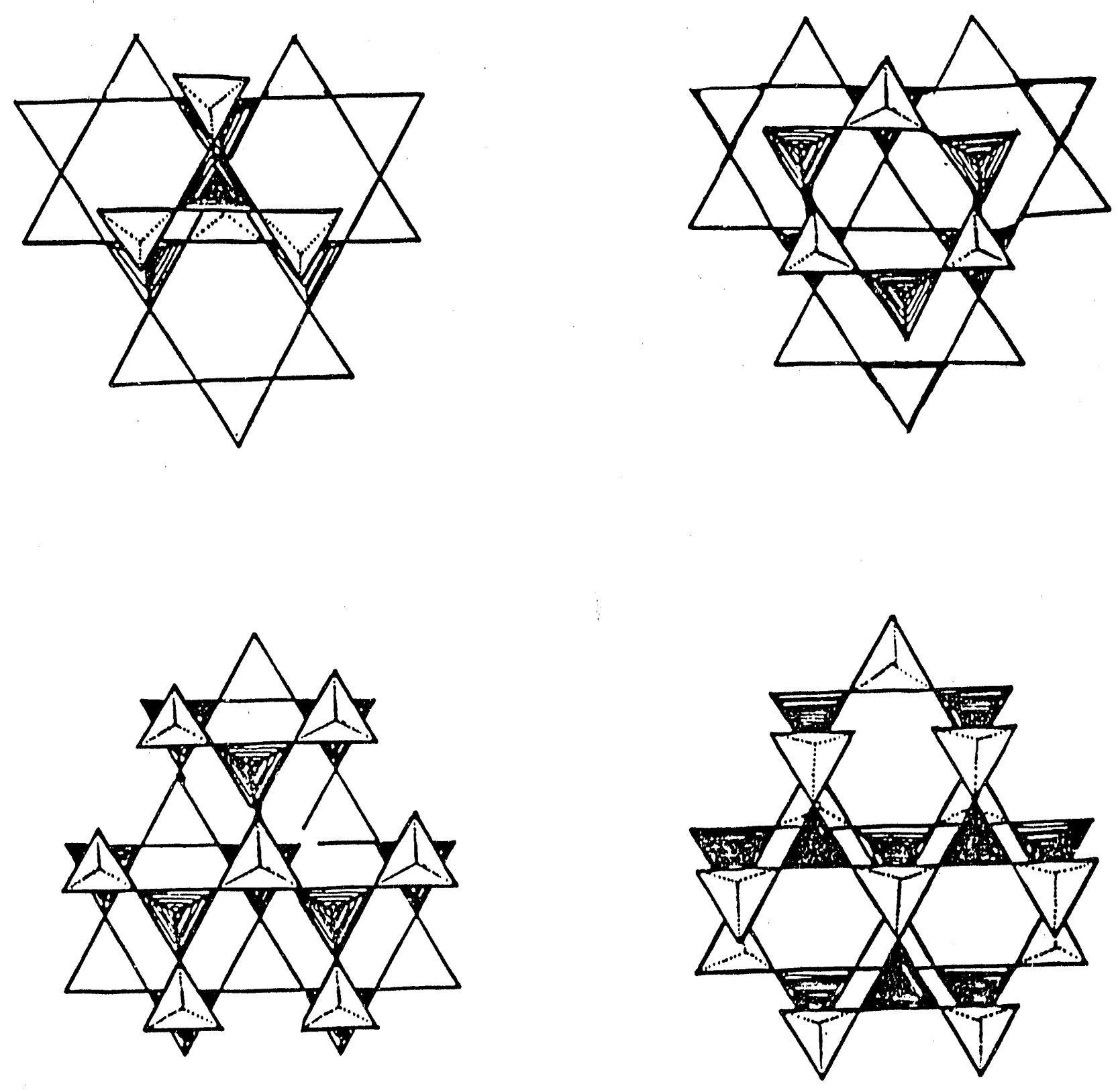

Fig. 7 The four sterically-viable local clusters of a three-dimensional network containing only primitive 6 -rings. 


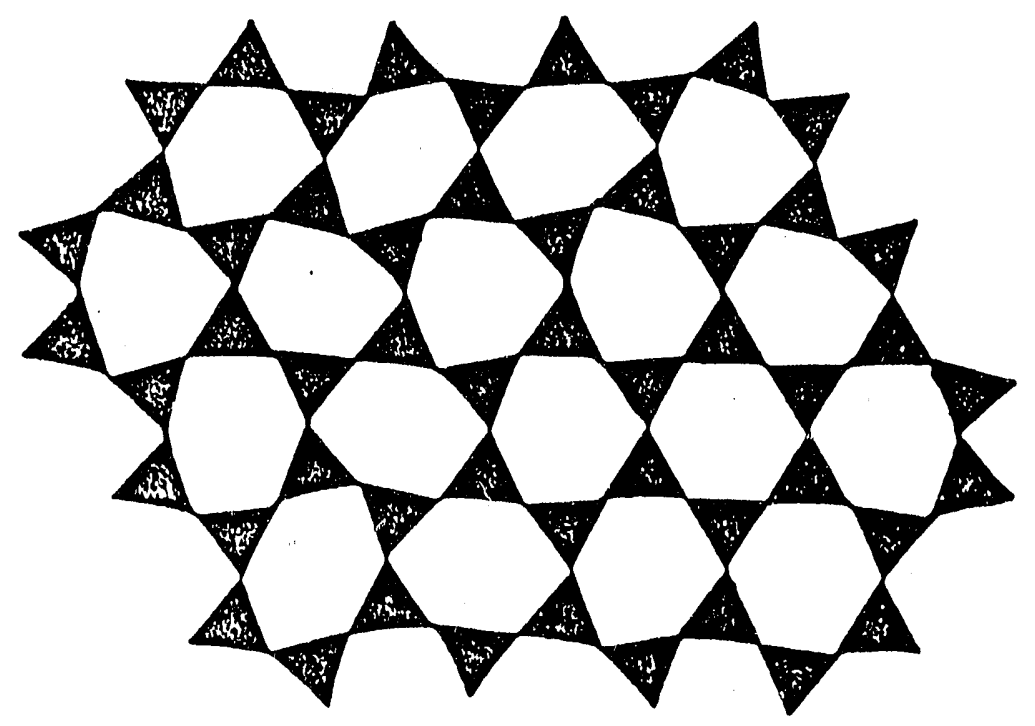

(a)

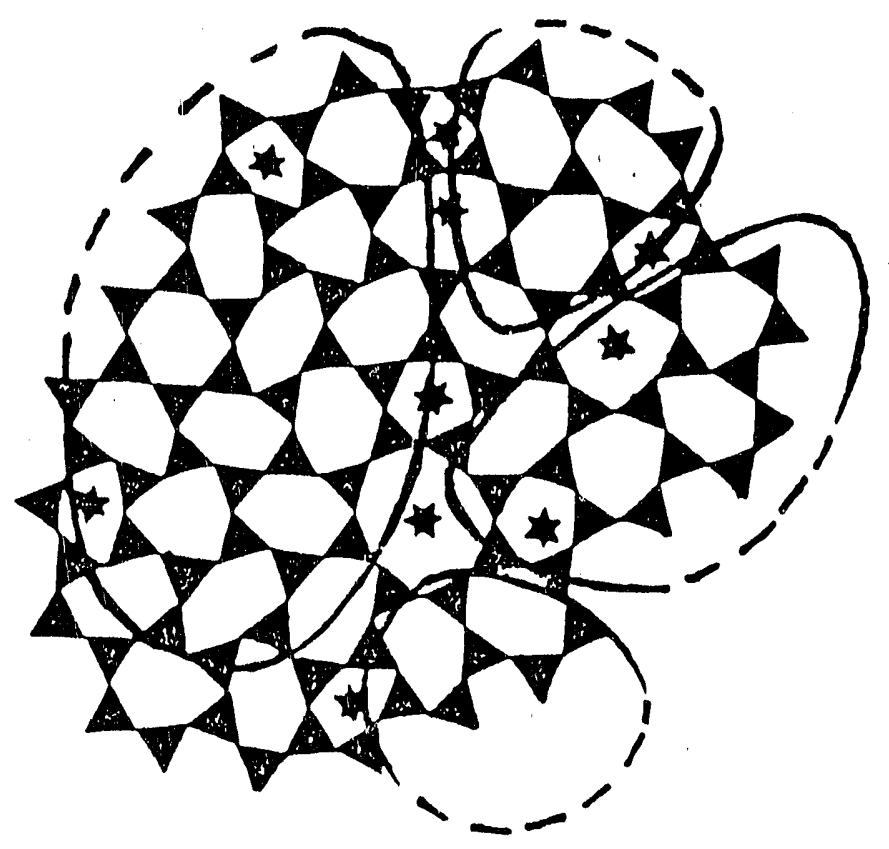

(b)

Fig. 8

a) A two-dimensional topologically-crystalline triangular network. b) Domains in a two-dimensional glass, dominated by 6-rings, which are bounded by lower- and higher-membered rings. 
in proposing a specific local network structure. It differs from the microcrystallite model in that there is no discrete boundary between the more- and less-ordered regions and the most-ordered regions are not truly crystalline. They are not formally crystalline because two-dimensional subnetworks are aperiodic as networks only; embedded in Euclidean space they are curved. Small networks of the ordered regions built with our allowed local cluster at each tetrahedron within two tetrahedra of the center, generated domains of order $2 \mathrm{~nm}$ diameter with about ten (if tridymite) layers; if the transition surface is three tetrahedron thick, the overall doman size comprises 17 tetrahedra and is $3.4 \mathrm{~nm}$ in diameter. 


\section{ELECTRON DIFFRACTION FROM APERIODIC STRUCTURES}

Diffraction techniques using X-ray, electron or neutron radiation are powerful methods in structure determination. For crystalline materials, the systematic correlation of atom positions due to the spatial periodicity of the crystal structure gives rise to discrete sharp diffraction peaks located at the reciprocal lattice points. For noncrystalline materials, however, the only correlation of atom positions is that due to interatomic bonds of closely prescribed lengths, and this gives a modulation of the diffraction intensities with a period roughly proportional to the reciprocal of the bond lengths. The diffraction patterns appear as diffuse halos smeared out into a quite uniform background.

$\mathrm{X}$-ray, neutron and electron diffraction have also been the most powerful techniques used in the studies of the structure of noncrystalline materials $[75-80]$ With electron diffraction, the very strong interaction with matter makes possible the analysis of very small volumes with acceptable statistics. X-ray or neutron diffraction experiments require relatively much larger samples, and thus the information obtained is an average over a larger volume of the sample. In diffraction experiments, both signals that contain structural information and noise that reduces the quality of the signals are collected, and these must be separated from each other for an accurate analysis to be made, or some technique must be applied to enhance the signal/noise ratio.

In an electron diffraction pattern of aperiodic structures, the interatomic interference, which is representative of the atomic radial distribution, smears into a background contributed by both elastic and inelastic atomic scattering. Among the major sources that contribute to the background noise of an electron diffraction pattern are energy fluctuations, arising from the energy distribution of the electron source and inelastic scattering events occurring as electrons pass through the thin sample. For a crystalline specimen, the Bragg diffraction peaks are positioned at a discrete set of locations, and thus the signal/noise ratio can be greatly enhanced by using spatial filtering techniques which are commonly utilized in image processing. When the specimen is non-crystalline, there are no Bragg peaks in the diffraction patterns, and spatial filtering becomes much more complicated, if not impossible.

Transmission electron diffraction has long been employed to investigate the structure of such disordered materials, particularly for thin film materials. It is also ideally suited 
to analysis of small electron-beam amorphized regions in silica thin films and the thin ionamorphized surface layers in ion-implanted materials which can be viewed in TEM crosssections. There are two ways to approach the structure solution: a) using the experimental intensity information to deduce the radial distribution function; and b) assuming a structure model and simulating the diffraction pattern of it which is then compared to experimental diffraction patterns. The latter method has been employed also to study crystallite structures in thin films $[81-83]$ With proper background reduction, the former method has been used to deduce radial distribution functions $[84-90]$.

Though energy-filtering has long been used to study the energy losses for spectroscopic analysis, it has not been equally well explored in diffraction studies. In an attempt to improve the resolution of their scanning electron diffraction instrument [91 - 93], Grigson and his colleagues installed an electrostatic energy filter [94], and the structure of amorphous germanium films deposited onto carbon substrates was investigated [95]. Graczyk and Moss [96] at MIT built a similar scanning unit and installed it in a transmission electron microscope. With such an instrument, studies were made on the structures of amorphous silicon [97], vapordeposited and ion-implanted thin films of amorphous germanium [98], and glow discharge amorphous silicon [99]. Recently the technique has been re-investigated by Cockayne and McKenzie [100] and their colleagues. With the use of modern energy-loss spectrometers, they studied both polycrystalline and amorphous materials, such as a hydrogenated amorphous silicon-carbon alloy [101], a boron- and phosphorus-doped hydrogenated amorphous silicon $[102]$, and $\mathrm{BN}[103]$.

\subsection{Theory of Energy-Filtered Electron Diffraction}

By elastic scattering we mean that the state of the atom is undisturbed due to the scattering processes. Although in general the collision between electrons and an atom is a many-body problem, to a very good approximation, it can be treated as a scattering problem in which the incident electron wave is scattered by the potential field of the atom [104]. In particular it is applicable to the so-called fast electron regime, when the incident electrons possess kinetic energies between $1 \mathrm{keV}$ and $10 \mathrm{MeV}$, encountered in electron microscopy experiments. Therefore the elastic scattering problem reduces to solving the Schrödinger equation with the potential term $V(\vec{r})$ being the atomic coulombic electrostatic potential. 
When there is an array of atoms positioned at $\vec{r}_{m}, m_{+}=1,2,3, \cdots$, the coherent scattering amplitude is the sum of all amplitudes scattered from each individual atom,

$$
F(\vec{s})=\sum_{m} f_{m} \exp \left(-2 \pi i \vec{s} \cdot \ddot{r}_{m}\right)
$$

where $f_{m}$ is the atomic scattering amplitude for atom $m$ positioned at $\vec{r}_{m}$ and $s=\frac{2 \sin \left(\frac{\oplus}{2}\right)}{\lambda}$, in which $\lambda$ is the electron wavelength and $\Theta$ the scattering angle. The intensity is

$$
I(\vec{s})=|F(\vec{s})|^{2}=\sum_{m} \sum_{n} f_{m} f_{n} \exp \left(-2 \pi i \vec{s} \cdot \vec{r}_{m n}\right)
$$

where $\vec{r}_{m n}=\vec{r}_{m}-\vec{r}_{n}$ is the interatomic vector between atoms $m$ and $n$.

If we define the atomic pair correlation function $P(\vec{r})$ in terms of the density function of scatterers $\rho(\vec{r})$ as the self-correlation function

$$
P(\vec{r})=\int \rho\left(\vec{r}^{\prime}\right) \rho\left(\vec{r}^{\prime}+\vec{r}\right) d \vec{r}^{\prime},
$$

the Fourier transform of the pair correlation function gives the scattering intensity

$$
I(\vec{s})=\int P(\vec{r}) \exp (-2 \pi i \vec{s} \cdot \vec{r}) d \vec{r}
$$

and the inverse Fourier transform of the scattering intensity function gives the pair correlation function

$$
P(\vec{r})=\int I(\vec{s}) \exp (2 \pi i \vec{s} \cdot \vec{r}) d \vec{s} .
$$

For crystals, the intensity distribution is a set of discrete Bragg peaks and the pair correlation function is the Patterson function [105 - 106].

When an array of atoms, considered as a rigid body, is allowed to take with equal probability all orientations in space, we have [107]

$$
\begin{aligned}
<\exp \left(-2 \pi i \vec{s} \cdot \vec{r}_{m n}\right)> & =\frac{1}{4 \pi r_{m n}^{2}} \int_{0}^{\pi} e^{-2 \pi i s r_{m n} \cos \phi} 2 \pi r_{m n}^{2} \sin \phi d \phi \\
& =\frac{\sin \left(2 \pi s r_{m n}\right)}{2 \pi s r_{m n}}
\end{aligned}
$$

and we come to the Debye formula [108] which gives the average intensity from an array of atoms that take all orientations equally in space,

$$
I(s)=\sum_{m} \sum_{n} f_{m} f_{n} \frac{\sin \left(2 \pi s r_{m n}\right)}{2 \pi s r_{m n}} .
$$


The pair correlation function is given by [109]

$$
P(r)=4 \pi \int_{0}^{\infty} I(s) \frac{\sin (2 \pi s r)}{2 \pi s r} s^{2} d s
$$

In general the atomic arrangement in a material can be described in terms of threedimensional pair-density functions $\rho_{i j}(\vec{r})$, which are proportional to the probability that there is a j-type atom at vector position $\vec{r}$ from an average $\mathrm{i}$-type atom. But for a system where the interatomic vectors have no preferred orientations, the density functions are spherically symmetrical, and the average scalar quantity $4 \pi r^{2} \rho(r) d r$ is the total number of atoms in a spherical shell of radius $r$ and thickness $d r$ about an atom. The function $4 \pi r^{2} \rho(r)$ is called the radial distribution function (RDF). The differential radial distribution function is defined as

$$
G(r)=4 \pi r^{2}\left[\rho(r)-\rho_{a}\right]
$$

where $\rho_{a}$ is the average density of atoms, and the reduced RDF is defined as

$$
D(r)=\frac{G(r)}{r}=4 \pi r\left[\rho(r)-\rho_{a}\right]
$$

In a multiconstituent material the total RDF can be expressed in terms of the partial RDFs $\rho_{i}(r)$ around each type of atom

$$
4 \pi r^{2} \rho(r)=4 \pi r^{2} \sum_{i=1}^{n} x_{i} \rho_{i}(r)
$$

where

$$
\rho_{i}(r)=\sum_{j=1}^{n} \rho_{i j}(r)
$$

$x_{i}$ is the fraction of each atom type, and $n$ is the number of different species.

Another often-used function is the so-called interference function defined as

$$
\begin{aligned}
S(s) & =2 \pi s \sum_{i \neq j} \exp \left[-2 \pi i \vec{s} \cdot\left(\vec{r}_{i}-\vec{r}_{j}\right)\right] \\
& =2 \pi s \int \rho(r) \exp (-2 \pi i \vec{s} \cdot \vec{r}) d \tau \\
& =8 \pi^{2} \int_{0}^{\infty} \rho(r) \sin (2 \pi s r) r d r
\end{aligned}
$$

which characterizes the correlation of the atom positions within the sample. 
For a monoatomic system, with $N$ atoms located at $\vec{r}_{m}$ in the sample, the scattering intensity is given by equation (2), which can also be expressed as

$$
I=N f^{2}+N f^{2} \int_{0}^{\infty} 4 \pi r^{2}\left[\rho(r)-\rho_{a}\right] \frac{\sin (2 \pi s r)}{2 \pi s r} d r
$$

Defining

$$
i(s)=\frac{I / N-f^{2}}{f^{2}}
$$

which is an experimentally observable quantity, we have

$$
s i(s)=2 \int_{0}^{\infty} r\left[\rho(r)-\rho_{a}\right] \sin (2 \pi s r) d r .
$$

Using the inverse Fourier transform, we obtain

$$
4 \pi r^{2} \rho(r)=4 \pi r^{2} \rho_{a}+8 \pi r \int_{0}^{\infty} s i(s) \sin (2 \pi s r) d s
$$

This result was first derived by Zernike and Prins [110].

In the above integration, however, the upper limit of infinity cannot be realized in data processing. In practice the integration is carried out up to a finite liruit $s_{\max }$ and a termination function $g(s)$ is usually applied. The final transformation is done over $g(s) s i(s)$ :

$$
\int_{0}^{s_{m a r}} g(s) \operatorname{si}(s) \sin (2 \pi s r) d s=\int_{0}^{\infty} g(s) \operatorname{si}(s) \sin (2 \pi s r) d s
$$

and this leads to the final result.

$$
\int_{0}^{\infty} g(s) \operatorname{si}(s) \sin (2 \pi r s) d s=\frac{1}{2} \int_{-\infty}^{+\infty} h(t)(r-t)\left[\rho(r-t)-\rho_{0}\right] d t
$$

where $h(r)$ is the cosine transform of $g(s)$ (assumed to be an even function).

It is clear from the above discussion that the Fourier transform of $s i(s) g(s)$ function (derived from experimental data) gives a convoluted radial distribution function.

\subsubsection{Multiple Component Systems}

When there is more than one type of atom existing in the sample, the intensity formula of equation ( 2 ) is still valid. Letting $x_{1}, x_{2}, \ldots, x_{n}$ be the atomic fraction of atoms of scattering amplitudes $f_{1}, f_{2}, \ldots, f_{n}$, we have

$$
I(s)=N \sum_{j=1}^{n} x_{j} f_{j}^{2}+N \sum_{i=1}^{n} \sum_{j=1}^{n} x_{j} f_{i} f_{j} \int_{0}^{\infty} 4 \pi r^{2} \rho_{i j}(r) \frac{\sin (2 \pi s r)}{2 \pi s r} \sigma(r) d r
$$


where $\sigma(r)$ is a function to allow for the finite size of scattering volume and $\rho_{i j}(r)$ the partial atomic density distribution function. Introducing a constant mean density of $\mathrm{j}$-type atoms $\bar{\rho}_{i j}$, we can then have

$$
\begin{gathered}
I(s)=N \sum_{j=1}^{n} x_{j} f_{j}^{2}+N \sum_{i=1}^{n} \sum_{j=1}^{n} x_{j} f_{i} f_{j} \int_{0}^{\infty} 4 \pi r^{2}\left[\rho_{i j}(r)-\bar{\rho}_{i j}\right] \frac{\sin (2 \pi s r)}{2 \pi s r} \sigma(r) d r+ \\
+N \sum_{i=1}^{n} \sum_{j=1}^{n} x_{i} f_{i} f_{j} \int_{0}^{\infty} 4 \pi r^{2} \bar{\rho}_{i j} \frac{\sin (2 \pi s r)}{2 \pi s r} \sigma(r) d r .
\end{gathered}
$$

The last term gives rise only to a very small contribution to the small-angle region [111]. Ignoring this term, we then obtain

$$
\begin{gathered}
I(s)=N \sum_{j=1}^{n} x_{j} f_{j}^{2}+ \\
+N \sum_{i=1}^{n} \sum_{j=1}^{n} x_{i} f_{i} f_{j} \int_{0}^{\infty} 4 \pi r^{2}\left[\rho_{i j}(r)-\bar{\rho}_{i j}\right] \frac{\sin (2 \pi s r)}{2 \pi s r} \sigma(r) d r .
\end{gathered}
$$

For a binary compound, $i, j=1,2$,

$$
\begin{gathered}
I(s)=N\left(x_{1} f_{1}^{2}+x_{2} f_{2}^{2}\right)+ \\
+N x_{1} f_{1}^{2} \int_{0}^{\infty} 4 \pi r^{2}\left[\rho_{11}(r)-\bar{\rho}_{11}\right] \frac{\sin (2 \pi s r)}{2 \pi s r} d r+ \\
+N x_{1} f_{1} f_{2} \int_{0}^{\infty} 4 \pi r^{2}\left[\rho_{12}(r)-\bar{\rho}_{12}\right] \frac{\sin (2 \pi s r)}{2 \pi s r} d r+ \\
+N x_{2} f_{2} f_{1} \int_{0}^{\infty} 4 \pi r^{2}\left[\rho_{21}(r)-\bar{\rho}_{21}\right] \frac{\sin (2 \pi s r)}{2 \pi s r} d r+ \\
+N x_{2} f_{2}^{2} \int_{0}^{\infty} 4 \pi r^{2}\left[\rho_{22}(r)-\bar{\rho}_{22}\right] \frac{\sin (2 \pi s r)}{2 \pi s r} d r
\end{gathered}
$$

Though the analysis of compounds is complicated by the multiple density functions and different scattering amplitudes for different kind of atoms, the Fourier technique is still valid. Ry rearranging the above equation, we can have

$$
s i(s)=\frac{f_{1}^{2}}{F^{2}} s i_{11}(s)+\frac{f_{1} f_{2}}{F^{2}} s i_{12}(s)+\frac{f_{2} f_{1}}{F^{2}} s i_{21}(s)+\frac{f_{2}^{2}}{F^{2}} s i_{22}(s)
$$

where

$$
s i(s)=s\left[I(s)-N\left(x_{1} f_{1}^{2}+x_{2} f_{2}^{2}\right)\right] / N F^{2}
$$


and

$$
s i_{i j}(s)=\int_{-\infty}^{+\infty} x_{p} r\left[\rho_{i j}(r)-\bar{\rho}_{i j}\right] \sin (2 \pi s r) d s .
$$

$F^{2}(s)$ is a normalizing function, typically, but not necessarily, equal to $\left(x_{1} f_{1}+x_{2} f_{2}\right)^{2}$.

As for the single component case, we apply a termination function $g(s)$ to obtain

$$
\begin{gathered}
2 \int_{0}^{\infty} g(s) s i(s) \sin (2 \pi s r) d s= \\
x_{1} \int_{-\infty}^{+\infty} Q_{11}(t)(r-t)\left[\rho_{11}(r-t)-\bar{\rho}_{11}\right] d t+ \\
+x_{1} \int_{-\infty}^{+\infty} Q_{12}(t)(r-t)\left[\rho_{12}(r-t)-\bar{\rho}_{12}\right] d t+ \\
+x_{2} \int_{-\infty}^{+\infty} Q_{21}(t)(r-t)\left[\rho_{21}(r-t)-\bar{\rho}_{21}\right] d t+ \\
+x_{1} \int_{-\infty}^{+\infty} Q_{22}(t)(r-t)\left[\rho_{22}(r-t)-\bar{\rho}_{22}\right] d t
\end{gathered}
$$

where

$$
Q_{i j}(t)=\int_{-\infty}^{+\infty} g(t) \frac{f_{i} f_{j}}{F^{2}} \cos (2 \pi s r) d s ; \quad i, j=1,2
$$

From this expression we can clearly see that one diffraction experiment is not sufficient to deduce the individual $\rho_{i j}(r)$ functions even though the $Q_{i j}$ functions are available.

One of the ways to obtain the individual $\rho_{i j}(r)$ functions is to carry out diffraction experiments using different types of radiation, e.g. X-rays and neutrons, as first suggested by Keating [112]. For a binary compounds the solution can be expressed as

$$
\begin{gathered}
4 \pi r^{2}\left[\rho_{1}-\rho_{0}\right]=\frac{8 \pi r}{x_{1}} \int_{0}^{\infty}\left[\frac{I_{1}(s)}{F_{11}}+\frac{I_{2}(s)}{F_{12}}+\frac{I_{3}(s)}{F_{13}}-1\right] s \sin (2 \pi s r) d s \\
4 \pi r^{2}\left[\rho_{2}-\rho_{0}\right]=\frac{8 \pi r}{x_{2}} \int_{0}^{\infty}\left[\frac{I_{1}(s)}{F_{21}}+\frac{I_{2}(s)}{F_{22}}+\frac{I_{3}(s)}{F_{23}}-1\right] s \sin (2 \pi s r) d s \\
4 \pi r^{2}\left[\frac{\rho_{12}}{x_{2}}-\rho_{0}\right]=-\frac{8 \pi r}{x_{1} x_{2}} \int_{0}^{\infty}\left[\frac{I_{1}(s)}{F_{31}}+\frac{I_{2}(s)}{F_{32}}+\frac{I_{3}(s)}{F_{33}}-1\right] s \sin (2 \pi s r) d s
\end{gathered}
$$

where $\rho_{0}=\frac{N-1}{N} \bar{\rho}$, and the Fs are appropriate combinations of the scattering factors of the two different types of atoms in the three diffraction experiments required, e.g.,

$$
F_{11}^{-2}=\left|\begin{array}{cc}
f_{2 b}^{2} & \left(f_{2 a}-f_{2 b}\right)^{2} \\
f_{3 b}^{2} & \left(f_{3 a}-f_{3 b}\right)^{2}
\end{array}\right| \div\left|\begin{array}{ccc}
f_{1 a}^{2} & f_{1 b}^{2} & \left(f_{1 a}-f_{1 b}\right)^{2} \\
f_{2 a}^{2} & f_{2 b}^{2} & \left(f_{2 a}-f_{2 b}\right)^{2} \\
f_{3 a}^{2} & f_{3 b}^{2} & \left(f_{3 a}-f_{3 b}\right)^{2}
\end{array}\right|
$$


where $f_{j a}$ and $f_{j b}(j=1,2,3)$, are the atomic scattering factors for elements $a$ and $b$ respectively in the $\mathrm{j}$-th diffraction experiment.

For a multiple component system, the intensity expression given by equation ( 2 ) is

$$
I(s)=\sum_{m} f_{m}^{2}+\sum_{m} f_{m} \sum_{n \neq m} f_{n} e^{-2 \pi i \vec{r} \cdot \vec{r}}
$$

when the approximation [113]

$$
f_{m}=K_{m} f_{e}
$$

is made, in which $K_{m}$ is a constant and $f_{e}$ is a function of $s$, but the same for all the atoms within the sample. Then we obtain

$$
I(s)=N \sum_{u c} f_{j}^{2}+N f_{e}^{2} \sum_{u c} K_{j} \int_{0}^{\infty} 4 \pi r^{2}\left[\rho_{j}(r)-\rho_{e}\right] \frac{\sin (2 \pi s r)}{2 \pi s r} d r
$$

where $N$ is the number of units of composition (or the number of chemical molecular units) and the summation is done over all the individual atoms within a defined unit of composition $u c$. Introducing the reduced intensity function

$$
i(s)=\left(\frac{I(s)}{N}-\sum_{u c} f_{j}^{2}\right) / f_{e}^{2}
$$

the related intensity function $s i(s)$ is then given in the form of a Fourier transform

$$
s i(s)=2 \int_{0}^{\infty} \sum_{u c} K_{j} r\left[\rho_{j}(r)-\rho_{e}\right] \sin (2 \pi s r) d r,
$$

and the radial distribution function $\rho_{j}(r)$ about a $j$ atom is given by an inverse Fourier transform in the form of a linear superposition of each kind of atom in the unit of composition

$$
\sum_{u c} K_{j} 4 \pi r^{2} \rho_{j}(r)=4 \pi r^{2} \rho_{e} \sum_{u c} K_{j}+8 \pi r \int_{0}^{\infty} s i(s) \sin (2 \pi s r) d s .
$$

In practice a convergence factor $e^{-4 \pi^{2} \alpha^{2} \rho^{2}}$ and a termination at $s_{\max }$ are applied, so that a slightly broadened quantity $\rho_{j}^{\prime}(r)$ is obtained. The positions of the peaks give the various interatomic distances in the sample.

As discussed in the previous section, the final curve obtained

$$
G(r)=4 \pi r^{2} \sum_{u c} K_{j}\left[\rho_{j}(r)-\rho_{e}\right]
$$


represents the linear superposition of radial distribution functions for each kind of atom in the unit composition. The maxima correspond to the various interatomic distances. In some cases these distances are enough to identify the kinds of atoms represented by the peak, and in these cases the peak area can be used to calculate the number of neighboring atoms. For example [111], in the radial distribution function for a sample of metamict $\mathrm{SiO}_{2}$, the first peak at $0.162 \mathrm{~nm}$ is from the nearest-neighbor silicon-oxygen separation, as occurs in crystalline silicas. The observed peak at $0.162 \mathrm{~nm}$ is the superposition of two peaks, one representing oxygens about an average silicon, and the other representing silicons about an average oxygen. The area of this peak is

$$
A=1 K_{S i} n_{O} K_{O}+2 K_{O} n_{S i} K_{S i}
$$

where $n_{O}$ and $n_{S i}$ are the numbers of nearest neighbor oxygens about a silicon and of nearest neighbor silicons about an oxygen. However, the stoichiometry gives $n_{O}=2 n_{S i}$, hence the peak area is given by

$$
A=2 K_{S i} K_{O} n_{O}
$$

From the measured peak area and the known value of $K_{S i}$ and $K_{O}$, the number of nearest neighbor oxygens about a silicon can be determined.

\subsubsection{Experimental Considerations for Electron Diffraction}

Although the procedures to derive RDFs appear to be straightforward, the final result is subject to a number of errors arising from such factors as misalignment, uncertainties in the shape of the atomic scattering amplitude, beam divergence, absorption effects, temperature factors and, most of all, from termination of the experimental data at finite scattering vectors. The presence of such errors probably accounts for the differences between various sets of data and the deduced RDFs. Therefore in the numerical procedure used to deduce the radial distribution functions, these errors must be eliminated in order to obtain any reliable results.

For simplicity, in the following treatment a single component system is assumed. Defining the reduced interference function $Q(s)$ as

$$
Q(s)=2 \pi s i(s)=2 \pi s\left[\frac{I / N}{f^{2}}-1\right]
$$


then from the definition of the reduced radial distribution function equation (10) we obtain the relationship

$$
Q(s)=\int_{0}^{\infty} D(r) \sin (2 \pi s r) d r
$$

The following data reduction procedure was proposed by Kaplow, Strong and Averbach [114]. In practice, the experimentally observed scattered intensity $I^{\prime}$ in arbitrary units is

$$
I^{\prime}=N I_{t}
$$

where $N$ is the number of scatterers which can be treated as a normalization constant, and $I_{t}$ is the theoretical value of the scattering intensity which approaches $f^{2}$ at large values of s. Therefore a plot of $I^{\prime} / f^{2}$ should approach a limiting value of $N$. This can be a convenient method of obtaining the normalization constant only when coherent radiation is significant.

When a fractional error $\frac{\Delta N}{N}$ in $N$ is introduced, the resultant error in the reduced interference function $Q(s)$ is

$$
\begin{gathered}
\Delta Q=2 \pi s \frac{\Delta N}{N}\left(\frac{I / N}{f^{2}}-1\right)+2 \pi s \frac{\Delta N}{N} \\
=\frac{\Delta N}{N} Q(s)+2 \pi s \frac{\Delta N}{N} .
\end{gathered}
$$

From the above expression it is seen that the error in $D(r)$ is then the true function modified by a change in scale plus the transform of a ramp of slope $\frac{\Delta N}{N}$. The transform of the ramp has the form

$$
\Delta D=\frac{\Delta N}{N}\left[\frac{\sin \left(2 \pi r s_{\max }\right)}{r^{2}}-\frac{2 \pi s_{\max } \cos \left(2 \pi r s_{\max }\right)}{r}\right]
$$

where $s_{\max }$ is the maximum value of $s$ (the termination value). The error function $\Delta D$ exhibits sharp oscillations at values of $r$ close to zero, and the absence of these sharp oscillations is thus a usual criterion for determining the correct value of the normalization constant $N$.

The termination parameter broadens the peaks in $D(r)$, but in the form of convoluting the data with a selection window. Another effect of these factors is to suppress the spurious oscillations in the radial distribution function curves. The broadening will cause a change in the area under the maxima of the RDF, which in turn can cause erroneous results in deducing the coordination numbers.

The procedure proposed by Kaplow et al. uses two criteria to correct the errors due to the termination effect: 
(i) A transform of $D(r)$ must reproduce the measured intensity function;

(ii) In the absence of other errors, the function $D(r)$ in the region below the first peak must be linear.

Their correction formula [114] yields the $D(r)$ function which is consistent with experimental data and is also physically plausible. The shape is correct below the first peak, and the corresponding intensity function extends smoothly beyond $s_{\max }$ in such a way that both the extension and the resultant $D(r)$ are physically reasonable.

\subsubsection{Inelastic Scattering and Multiple Scattering}

From previous discussions it is ciear that in order to obtain the partial radial distribution functions, more than one diffraction experiment is required. Instead of using different types of radiation as discussed in Section 4.1.2, an alternative could be to use the inelastically scattered electrons with a characteristic energy loss as has been well-discussed for the $\mathrm{X}$-ray case [115]. By choosing a characteristic energy loss, e.g., the K-edge absorption energy of an element in the compound, one can collect reflections that have only experienced a single inelastic scattering event. For a binary compound composed of elements $a$ and $b$, one can choose to use the K-edges of $a$ and $b$ respectively. In addition to the elastic diffraction data one can therefore obtain three sets of diffraction data, and the systematic equations can be solved to obtain the partial radial distribution functions.

The effects of multiple scattering will complicate the analysis. Since the interaction between electrons and matter is much stronger than the interaction between $\mathrm{X}$-ray photons and matter, multiple scattering is important in electron diffraction. Though the multiple scattering of $\mathrm{X}$-rays is relatively weak, it is not always negligible as demonstrated by Warren and Mozzi [116]. In this case corrections are required.

For electron diffraction, however, though the importance of multiple scattering in crystal diffraction has been well recognized [117], it is much less conclusive for the case of diffraction of noncrystalline materials. Early results [118-119] show that the multiple scattering is also important for diffraction of non-crystalline materials, but recent arguments [120] show that the dynamical diffraction formulae can be reduced to equivalent kinematical form so that the kinematic theory gives reliable results. It has been pointed [121] that the 
effect of multiple scattering could lead to erroneous results when the coordination number is calculated using kinematic formulae.

Since the kinematic approximation has always been used in data analysis, it is necessary to investigate the multiple scattering effects in detail. We are currently investigating this effect by using digital simulations.

\subsubsection{Instrumentation}

Energy-selecting instruments have been constructed in various laboratories. Grigson [78] constructed a diffraction camera which is capable of collecting directly the energy-filtered electron diffraction data sequentially with a scanning unit. The energy filtering was realized [122] by using a retarding electrostatic field, and a post-specimen coil was used to scan the diffraction pattern. Graczyk and Moss [123] incorporated an energy-filtered direct recording arrangement into a transmission electron microscope, which combines both electron microscopy and direct recording of electron diffraction patterns. Recently Cockayne and co-workers [100] used post-specimen scanning coils positioned close to the back focal plane of the objective lens to scan the diffraction pattern across the entrance aperture of an energy-selecting spectrometer to collect the diffraction pattern in a sequential mode. Recent advances have now made possible energy-filtered electron diffraction and imaging to be realized in the same microscope and the recording of the image and corresponding selected area diffraction pattern in the parallel mode [124-125]. We initially used this type of instrument (Zeiss CM902) at the Harvard School of Public Health to acquire energy-filtered electron diffraction patterns operating at $80 \mathrm{kV}$ with an energy selection window of about $20 \mathrm{eV}$. Presently, we are using a field-emission scanning transmission electron microscopes (VG HB5) at MIT operating at $100 \mathrm{kV}$, to collect energy-filtered electron diffraction patterns in the selected area diffraction mode with a $2 \mathrm{eV}$ energy window. A selected area aperture $30 \mu \mathrm{m}$ in diameter was used to limit recorded patterns to a $10 \mu \mathrm{m}$ specimen area; a $10 \mu \mathrm{m}$ aperture is also available. A collector aperture of $70 \mu \mathrm{m}$ determines the angular resolution of the diffraction patterns at $7 \times 10^{-5}$ radians. The small size of the electron probe is important in our experiments, as this can reduce the illuminated area in a minimum while maintaining quite parallel illumination. This allows us to avoid unwanted damage to the sample and the amorphization time is also increased. At MIT the installation of a new field-emission STEM 
(VG HB603) has just been completed. The new microscope can be operated up to $300 \mathrm{kV}$ with post-specimen scanning coils; the post-specimen scanning coils can further reduce the errors introduced during beam scanning. The high brightness of the fild emission gun operating at $300 \mathrm{kV}$ will provide a more efficient electron radiation source and thicker samples can be analyzed without sacrificing the signal/noise ration which is vital in STEM diffraction studies. Due to more advanced design, an even smaller probe size of about $0.3 \mathrm{~nm}$ can be obtained, and very small area microdiffraction is possible.

\subsection{Preliminary Results and Discussions}

Preliminary energy-filtered diffraction data were obtained from the VG HB5 STEM at MIT from four different forms of aperiodic silica, using the experimental conditions described in Section 4.1.4. Both halo diffraction patterns and line-scan profile of the diffraction pattern were recorded at zero loss. Intensity plots of $I(s)$ vs $s$ were obtained by digitizing the linescan profiles and calibrating against crystalline peaks in partially-amorphized quartz. Radial distribution functions were reconstructed from the intensity plots using algorithms described in Section 4.1.

The four aperiodic silicas examined were vitreous silica of very low water content (<5ppm) obtained from Dr. David Griscom at Naval Research Laboratory; $100 \mathrm{keV}$ electronamorphized $\alpha$-quartz with the electron beam directed initially along a $<120>$ direction; $\alpha$ quartz amorphized using $1.5 \times 10^{24} \mathrm{n} / \mathrm{m}^{2}$ fast neutron fluence; and ion-araorphized $\alpha$-quartz implanted along $<120>$ with $150 \mathrm{keV} \mathrm{Si}{ }^{+}$ions to a fluence of $2 \times 10^{21} \mathrm{Si}^{+} / \mathrm{m}^{2}$. All samples were mechanically sectioned, thinned to electron transparency by $5 \mathrm{kV}$ argon ion milling and coated with $10 \mathrm{~nm}$ amorphous carbon to preclude charge acquisition in the electron beam.

Fig. 10 shows the intensity profile for the vitreous silica sample. The profile was acquired with minimal prior electron irradiation so as not to alter the initial aperiodic state to the metamict structure, presuming this could happen under electron as well as neutron irradiation. The radial distribution function reconstructed from the intensity profile is shown in Fig. 11 and accords well with RDFs calculated for vitreous silica from X-ray and neutron diffraction data [126]. Figs. 12 and 13 present similar information for the electron-amorphized $\alpha$-quartz which are similar to those for vitreous silica but nevertheless exhibit some significant differences. It takes $10-15$ minutes to completely amorphize quartz in the VG HB5 



Fig. 10 (above) Zero-loss scattered intensity distribution for vitreous silica obtained by digitizing electron diffraction scan profiles.

Fig. 11 (below) Radial distribution function for vitreous silica reconstructed from the intensity data in Fig. 10. 



Fig. 12 (above) Zero-loss scattered intensity distribution for electron-amorphized $\alpha$ quartz.

Fig. 13 (below) Radial distribution function for electron-amorphized $\alpha$-quartz reconstructed from the intensity data in Fig. 12. 

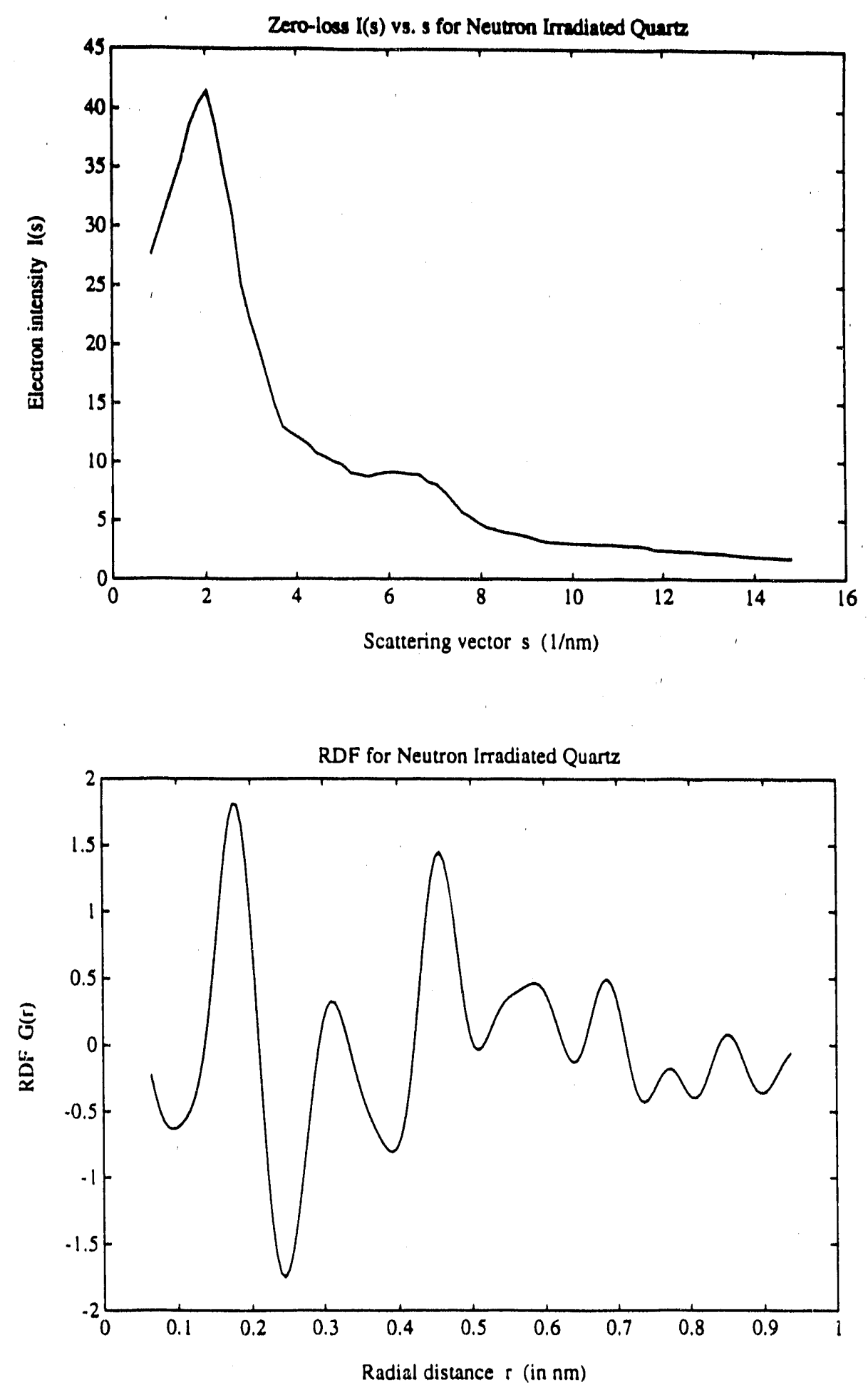

Fig. 14 (above) Zero-loss scattered intensity distribution for fast neutron-amorphized $\alpha$-quartz irradiated to $1.5 \times 10^{20} \mathrm{n} / \mathrm{m}^{2}$.

Fig. 15 (below) Radial distribution function for neutron-amorphized quartz reconstructed from the intensity data in Fig. 14. 


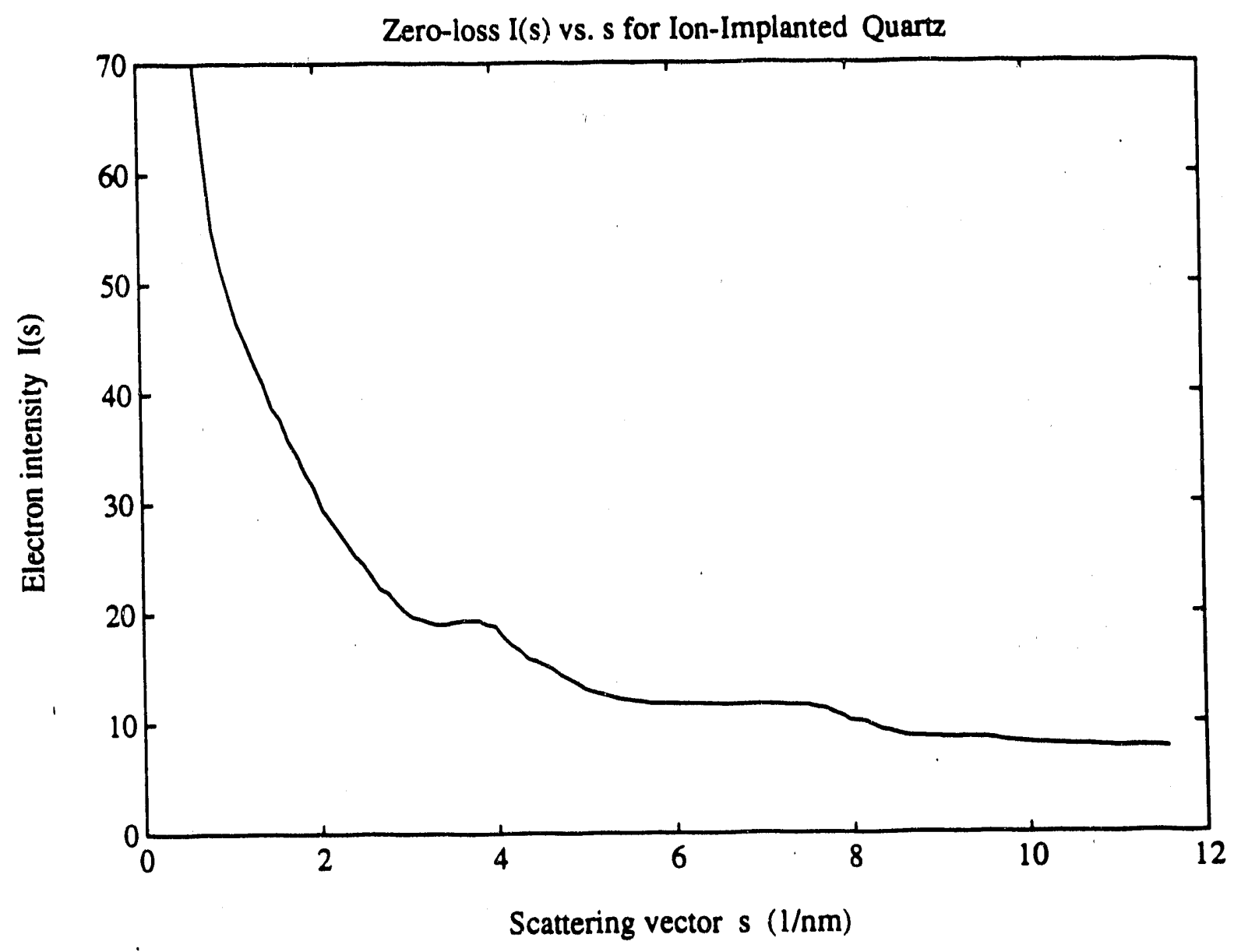

Fig. 17 Zero-loss scattered intensity distribution for ion-amorphized $\alpha$-quartz. The large selected-area aperture in the STEM included some underlying crystalline material. 
STEM under the conditions utilized in acquiring the diffraction profiles, so there is plenty of opportunity to investigate intermediate states. Figs. 14 and 15 present the equivalent information from the neutron-amorphized $\alpha$-quartz, which a previous TEM study [142] had shown to amorphize completely between $7 \times 10^{23}$ and $1.5 \times 10^{24} \mathrm{n} / \mathrm{m}^{2}$ fast neutron fluences. These differ significantly from both vitreous silica and electron amorphized quartz. Zero-loss scans were also produced from quartz neutron-irradiated to $3 \times 10^{23} \mathrm{n} / \mathrm{m}^{2}$ in which substantial crystallinity was still apparent, but also a diffuse halo. An intermediate dose, $7 \times 10^{23} \mathrm{n} / \mathrm{m}^{2}$, will be examined shortly to see if there is sufficient information in the halo to deduce an RDF. Fig. 16 shows a cross-section TEM image of the $\mathrm{Si}^{+}$-amorphized $\alpha$-quartz, indicating an amorphization depth of nearly $500 \mathrm{~nm}$, right to the end of the ion range. Unfortunately the selected area aperture installed in the VG HB5 selected an area substantially larger than this, so it was not possible to extract zero-loss diffraction profiles purely from the amorphized region above; but the profiles obtained, Fig. 17, do reveal again differences from the other aperiodic silicas, particularly a characteristic smearing of the first strong diffraction peak. RDF reconstruction will be performed on better data obtained when a smaller selected-area aperture is installed in the HB5.

These preliminary results have demonstrated the feasibility of using energy-filtered diffraction information acquired in the STEM for the proposed study of aperiodic ceramir structures, information (for at least two of the cases) which could not have been acquired any other way. From the reconstructed RDFs, we can see that at least three of the structures are quite different from one another, though all of them are uniformly amorphized silicas. This was expected, because we know at least two of them (for which bulk density measurements are possible) have different densities. The common feature is that the first peak in the RDFs appears much the same, which implies that the basic $\left[\mathrm{SiO}_{4}\right]$ tetrahedron remains unchanged. At medium range, however, the structures diverge, and a detailed analysis with progressively better data is now being made of the differences.

A first attempt was made to acquire diffraction data at energy losses corresponding to the absorption edges of $\mathrm{Si}$ and $\mathrm{O}$, without initial success due to poor statistics. We expect that the VG HB603 STEM, particularly if equipped with parallel electron energy-loss spectrometry (PEELS) as anticipated, will improve the situation sufficiently to acquire such information from which to reconstruct partial radial distributions. 


\section{THE METAMICT TRANSFORMATION IN POLYPHOSPHATE CERAMICS}

$\left[\mathrm{PO}_{4}\right]$ tetrahedra, like $\left[\mathrm{SiO}_{4}\right]$ tetrahedra, can link up together by corner sharing oxygen atoms to form polymerized structures up to and including three-dimensional glassy networks [127, 128]. While pure $\mathrm{P}_{2} \mathrm{O}_{5}$ is unstable in moist air, addition of metal cations (as metal oxides) stabilizes the $\left[\mathrm{PO}_{4}\right]$ linkages in chains or rings. Lead phosphate glasses have been investigated for decades because their low preparation temperatures and low softening points have made them ideal subjects for fundamental studies of glass properties, such as the glass transition and devitrification.

A portion of the $\mathrm{PbO}-\mathrm{P}_{2} \mathrm{O}_{5}$ psuedo-binary phase diagrams is shown in Fig. 18. The principal crystalline compounds are lead metaphosphate $\left(\mathrm{PbO} \cdot \mathrm{P}_{2} \mathrm{O}_{5}\right.$ or $\left.\mathrm{Pb}\left(\mathrm{PO}_{3}\right)_{2}\right)$, lead pyrophosphate $\left(2 \mathrm{PbO} \cdot \mathrm{P}_{2} \mathrm{O}_{5}\right.$, or $\left.\mathrm{Pb}_{2} \mathrm{P}_{2} \mathrm{O}_{7}\right)$ and lead orthophosphate $\left(3 \mathrm{PbO} \cdot \mathrm{P}_{2} \mathrm{O}_{5}\right.$ or $\left.\mathrm{Pb}_{3}\left(\mathrm{PO}_{4}\right)_{2}\right)$; the orthophosphate lies in a complicated part of the phase diagram, with several other line compounds nearby, and has a much higher melting point. Large optical-quality single crystals of the crystalline pyrophosphate $\mathrm{Pb}_{2} \mathrm{P}_{2} \mathrm{O}_{7}$ can be grown to dimensions $5 \times 5$ $\times 1 \mathrm{~mm}^{3}$ and have been used to determine the structure of this compound [129], which consists of sheets of $\mathrm{P}_{2} \mathrm{O}_{7}$ diphosphate dimer groups coordinated to the large $\mathrm{Pb}^{2+}$ cations in four non-equivalent sites.

Unlike their silicate counterparts, the phosphate chains and rings do not significantly alter their state of polymerization when dissolved into aqueous solutions $[130,131]$. Their stability permits liquid chromatography to provide information regarding the degree of $\left[\mathrm{PO}_{4}\right]$ unit polymerization in the original solid with far more reliability than equivalent techniques (e.g. trimethylsilylation) do for silicates. High-performance liquid chromatographic (HPLC) techniques have been used recently to assess polymerization in melt-derived lead-iron phosphate glasses $[132,133]$ and in lead phosphate glasses in various stages of devitrification [134]. Lead metaphosphate glass, for example, consists of long polymeric chains of edgesharing $\left[\mathrm{PO}_{4}\right]$ tetrahedra (average chain length $>15\left[\mathrm{PO}_{4}\right]$ tetrahedra), bonded more weakly to adjacent chains via $\mathrm{Pb}^{2+}$ cations and the non-bridging oxygens in the phosphate chains [132-134]. The average chain length in lead pyrophosphate glass is closer to two [135]. The addition of iron, which goes into octahedral sites, stabilizes this glass still further against 


\section{$\mathrm{PbO}-\mathrm{P}_{2} \mathrm{O}_{3}$}
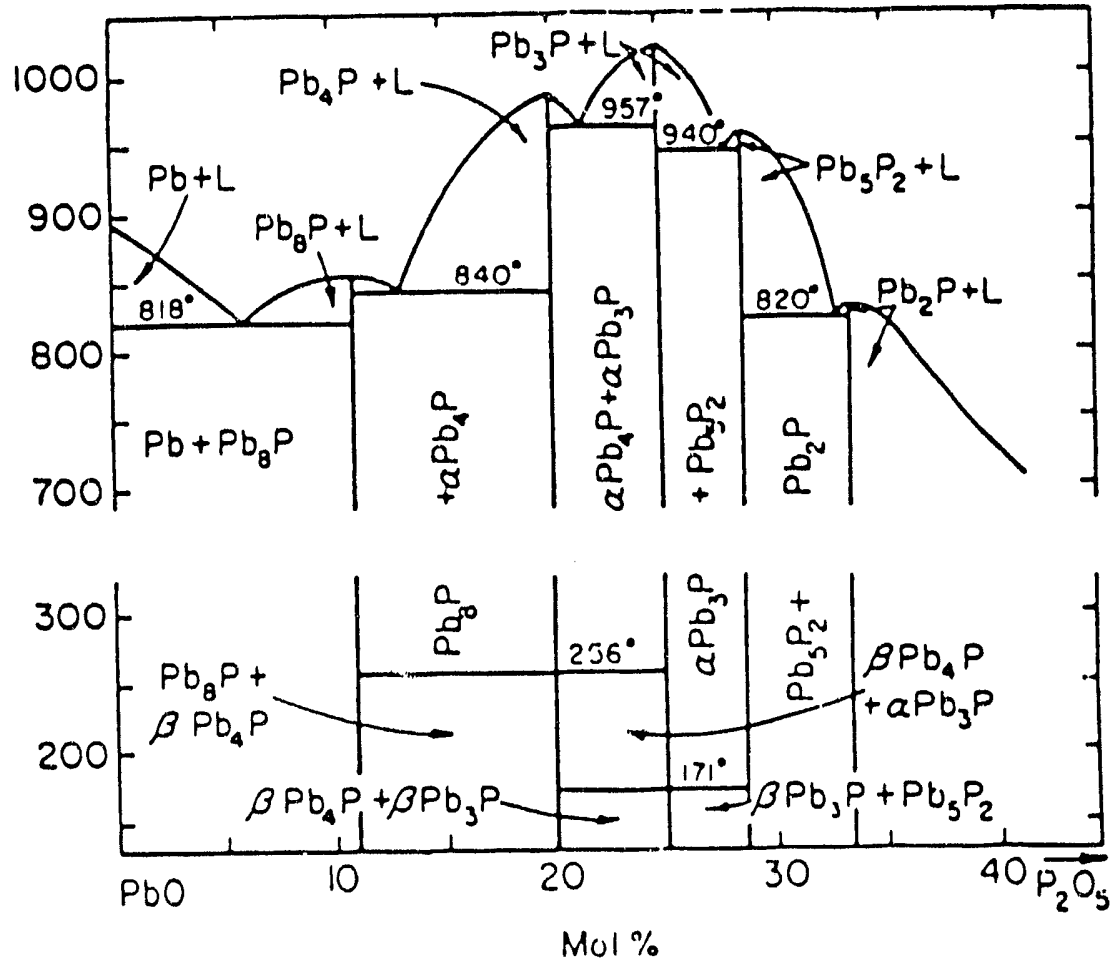

Fig. 18. $\quad \mathrm{PbO}-\mathrm{P}_{2} \mathrm{O}_{5}$ pseudo-binary phase diagram [after H.H. Paetsch and A. Dietzel, Glastech. Ber. 29 (1956) 348]. In this diagram, $\mathrm{PbO}$ is abbreviated as $\mathrm{Pb}, \mathrm{P}_{2} \mathrm{O}_{5}$ as $\mathrm{P}$, and liquid as $\mathrm{L}$. 
dissolution in aqueous solutions $[134,136,137]$.

More recently, Sales et al. [138,139] have examined the near-surfaces of lead pyrophosphate single crystals and lead pyrophosphate glass amorphized using $540 \mathrm{keV} \mathrm{Pb}^{3+}$ and $55 \mathrm{keV} \mathrm{O}{ }^{2+}$ ion implantation at fluences of $10^{15}-10^{19} \mathrm{~Pb}^{3+} / \mathrm{m}^{2}$ and $10^{17}-10^{21} \mathrm{O}^{2+} / \mathrm{m}^{2}$ respectively. The implantation depth distribution in both cases peaked at about $75 \mathrm{~nm}$. The implanted surfaces were analyzed using Rutherford back-scattering (RBS) and HPLC. RBS indicated that the single crystals amorphized at $\mathrm{Pb}^{3+}$ ion doses of $10^{17}-10^{18}$ ions $/ \mathrm{m}^{2}$ were significantly disordered to a depth of $200 \mathrm{~nm}$, at the extreme end-of-range. Calorimetry established that the lead pyrophosphate glass had a glass transition $T_{g} \approx 663 \mathrm{~K}$ and crystallized exothermically at 707K. HPLC revealed that the phosphate chain length distribution was identical for both $\mathrm{Pb}^{3+}$ - and $\mathrm{O}^{2+}$ - amorphized surfaces but significantly different from that found in lead pyrophosphate glass produced by cooling from the meit. In particular, the distribution extends to much longer phosphate chains in the ionamorphized material and longest in the ion-amorphized crystal. This result suggests that the metamict structure forms by a quite different mechanism than envisaged [140] for formation of the thermal glass from the melt. It also echoes our results for silicas, described in Section 4.2 , in which the structures of the thermal glass, the ion-amorphized crystal and the electronamorphized crystal are all different, as deduced by energy-filtered electron diffraction.

\subsection{Current Results from Lead Pyrophosphate and Lead Metaphosphate}

Because the Sales $e t$ al. ion implantation work on lead pyrophosphate accomplished a portion of what we had originally proposed and came out at the beginning of our funding period, we have had to be content to supplement and extend their work, in particular adding energy-filtered electron diffraction and high-resolution TEM as analytical tools, using $\mathrm{P}^{+}$ rather than $\mathrm{Pb}^{3+}$ and $\mathrm{O}^{2+}$ as the implanted ion, and extending the range of lead phosphate compositions to the metaphosphate compositions which are characterized by initially longer phosphate chains. Further extension to other phosphate structures is proposed in Section 5.2 .

Because their samples were not made available to us, as originally anticipated, we have developed our own procedure for manufacturing phosphate single crystals and glasses. 
$\mathrm{Pb}_{2} \mathrm{P}_{2} \mathrm{O}_{7}$ single crystals were prepared by slow cooling of a melt of equimolar ratios of 99.9999\% pure lead oxide $(\mathrm{PbO})$ and $99.9999 \%$ pure ammonium dihydrogen phosphate $\left(\left(\mathrm{NH}_{4}\right)_{2} \mathrm{H}_{2} \mathrm{PO}_{4}\right)$ in a platinum crucible at ambient furnace atmosphere. Batches comprising these two compounds in powder form were first heated to $775 \mathrm{~K}$ at $100 \mathrm{~K} / \mathrm{h}$ and were then held for $1 \mathrm{~h}$, during which the $\mathrm{NH}_{3}$ and water produced as a result of decomposition of $\left(\mathrm{NH}_{4}\right) \mathrm{H}_{2} \mathrm{PO}_{4}$ were allowed to escape. Batches were then heated at the same rate to 1175 $\mathrm{K}$ and held for $10 \mathrm{~h}$ to form a low viscosity homogeneous liquid. This liquid was cooled at a rate of $1 \mathrm{~K} / \mathrm{h}$ to $950 \mathrm{~K}$, and then subsequently cooled to room temperature at a rate of $50 \mathrm{~K} / \mathrm{h}$ to obtain large, transparent, micaceous single crystals of $\mathrm{Pb}_{2} \mathrm{P}_{2} \mathrm{O}_{7}$. Although single crystals as large as $18 \times 15 \times 2 \mathrm{~mm}^{3}$ could be obtained, the average size of the single crystals which could be extracted was $8 \times 6 \times 0.5 \mathrm{~mm}^{3}$. Attempts to grow large single crystals of lead metaphosphate and lead orthophosphate compositions are in progress.

$\mathrm{Pb}_{2} \mathrm{P}_{2} \mathrm{O}_{7}$ glasses were prepared by quenching the same melt (in the platinum crucible) at $1175 \mathrm{~K}$ between two thick copper plates $\left(300 \times 250 \times 12.5 \mathrm{~mm}^{3}\right)$ at a quenching rate expected to be of order $1000 \mathrm{~K} / \mathrm{s}$. The glass was then immediately transferred to a specially designed refractory boat preheated to $650 \mathrm{~K}$ ( $20 \mathrm{~K}$ below the $\mathrm{T}_{\mathrm{g}}$ of the glass) which in turn was transferred to a furnace maintained at the same temperature. The glass was annealed at this temperature for $1 \mathrm{~h}$ and then cooled to room temperature at a rate of $50 \mathrm{~K} / \mathrm{h}$. Using this technique, shattering of the glass due to residual stresses arising as a consequence of a high quenching rate was minimized, and large $\left(40 \times 30 \times 0.3 \mathrm{~mm}^{3}\right)$, mechanically stable, transparent lead pyrophosphate glasses could easily be prepared.

Lead metaphosphate $\left(\mathrm{PbO} \cdot \mathrm{P}_{2} \mathrm{O}_{5}\right)$ glass was prepared by mixing appropriate amounts of powders of lead oxide and ammonium dihydrogen phosphate (of previously mentioned purity levels) and following the same heating schedule as for the lead pyrophosphate glass. However, instead of quenching between two copper plates, the melt was poured in graphite molds preheated to $574 \mathrm{~K}\left(20 \mathrm{~K}\right.$ below $\left.\mathrm{T}_{\mathrm{g}}\right)$ and the mold with the glass in it immediately transferred to a furnace held at the same temperature. The glass was annealed at this temperature for $1 \mathrm{~h}$ and then cooled to room temperature at a rate of $50 \mathrm{~K} / \mathrm{h}$. Glasses whose compositions lay in the range between the lead metaphosphate composition $\mathrm{PbO} \cdot \mathrm{P}_{2} \mathrm{O}_{5}$ and the composition $1.5 \mathrm{PbO} \cdot \mathrm{P}_{2} \mathrm{O}_{5}$ were also prepared using the same technique. 
As noted earlier, phosphate glasses leach rapidly in water. Although the compositions prepared so far are expected to be stable in ambient humid air, all of the phosphates once cooled down to room temperature were transferred to a vacuum desiccator and then stored in an extremely dry (relative humity less than 2\%) $\mathrm{N}_{2}$-atomsphere glove box. In addition, the raw materials, $\mathrm{PbO}$ and $\left(\mathrm{NH}_{4}\right) \mathrm{H}_{2} \mathrm{PO}_{4}$, were also stored in the same glove box to eliminate batching inconsistencies due to moisture adsorption.

$\mathrm{X}$-ray powder diffraction measurements, performed on crushed single crystals, confirmed that they were phase pure. Refinement yielded the following triclinic crystal parameters: $\mathrm{a}=6.961(3) \AA, \mathrm{b}=6.978(5) \AA, \mathrm{c}=12.774(7) \AA, \alpha=83.11(8)^{\circ}, \beta=91.14(4)^{\circ}$ and $\gamma=90.21(5)^{\circ}$. Measurements were also made on glasses and confirmed their aperiodic state. In addition, Laue back reflection measurements were performed on the lead pyrophosphate single crystals to confirm that they were single crystals and that the cleavage planes were orthogonal to the c-axis. DSC measurements were made for all glasses at a heating rate of $10 \mathrm{~K} / \mathrm{min}$ on a Seiko DSC $320 \mathrm{H} 5200$ high-temperature thermal analysis system. The glass transition temperatures for all of the well-annealed glasses were determined and are presented in Table 2.

\section{Table 2. Glass Compositions and Corresponding Glass Transition Temperatures}

\begin{tabular}{||c|c||}
\hline Glass Composition & $\mathrm{T}_{\mathrm{g}}(\mathrm{K})$ \\
\hline $1.0 \mathrm{PbO} \cdot \mathrm{P}_{2} \mathrm{O}_{5}$ & 594 \\
$1.1 \mathrm{PbO} \cdot \mathrm{P}_{2} \mathrm{O}_{5}$ & 598 \\
$1.2 \mathrm{PbO} \cdot \mathrm{P}_{2} \mathrm{O}_{5}$ & 600 \\
$1.3 \mathrm{PbO} \cdot \mathrm{P}_{2} \mathrm{O}_{5}$ & 602 \\
$1.4 \mathrm{PbO} \cdot \mathrm{P}_{2} \mathrm{O}_{5}$ & 616 \\
$2.0 \mathrm{PbO} \cdot \mathrm{P}_{2} \mathrm{O}_{5}$ & 670 \\
\hline
\end{tabular}

None of the glasses exhibited multiple glass transition temperatures, and the difference between $T_{g}$ and the crystallization temperatures was of order only $50-75 \mathrm{~K}$, 
and parallel-section TEM samples for energy-filtered electron diffraction (see Section 4), high-resolution electron microscopy, liquid phase chromatography/flow injection analysis (HPLC-FIA) and other analyses (discussed in Section 5.2). Figs. 20 and 21 show bright-field zero-loss XTEM STEM cross-section images of implanted pyrophosphate and metaphosphate glass samples, showing observable structural alteration to depths of $150 \mathrm{~nm}$ and $225 \mathrm{~nm}$ respectively. Electron microprobe analysis $(1.5 \mathrm{~nm}$ spot size) revealed precipitation of anomalously $\mathrm{Pb}$-rich domains in the implantation zone, corresponding to the TEM image contrast anomalies. This loss of $\mathrm{Pb}$ is expected to have had a significant impact on the phosphate group linkage. Difficulty has been experienced in preparing XTEM specimens implanted single-crystal pyrophospate because of the micaceous clevage planes normal to the implantation directions. Lead pyrophosphate single crystals were also submitted to the spallation neutron source at Los Alamos Meson Physics Facility (LAMPF) for fast neutron irradiation. These have now been irradiated at a temperature of $333 \mathrm{~K}$ to a fluence of $2 \times 10^{24} \mathrm{n} / \mathrm{m}^{2}$ (fission-like spectrum, with a high energy tail $>20 \mathrm{MeV}$ ). This fluence is sufficient to completely amorphize quartz [142]. The neutron-irradiated samples will be shipped pending acceptable loss of activity.

Conventional and high-resolution 200-keV transmission electron microscopes were used for the initial screening of the single crystal and glassy phosphates. Fig. 19 shows an HREM image projected along the [001] axis andits accompanying electron diffraction patter.

TEM specimens of all but the ion-amorphized crystalline pyrophosphates were subsequently investigated in an energy-filtered diffraction mode in the VG HB5 STEM. Figs. 22 and 23 show zero-loss (1.5 eV window) electron diffraction profiles from unimplanted and $\mathrm{P}^{+}$-implanted lead pyrophosphate and lead metaphosphate glasses in which substantial differences are evident in the nature of the intermediate-range order. Both implanted glasses show distinct intensity reductions in the first sharp diffraction peak (FSDP). 

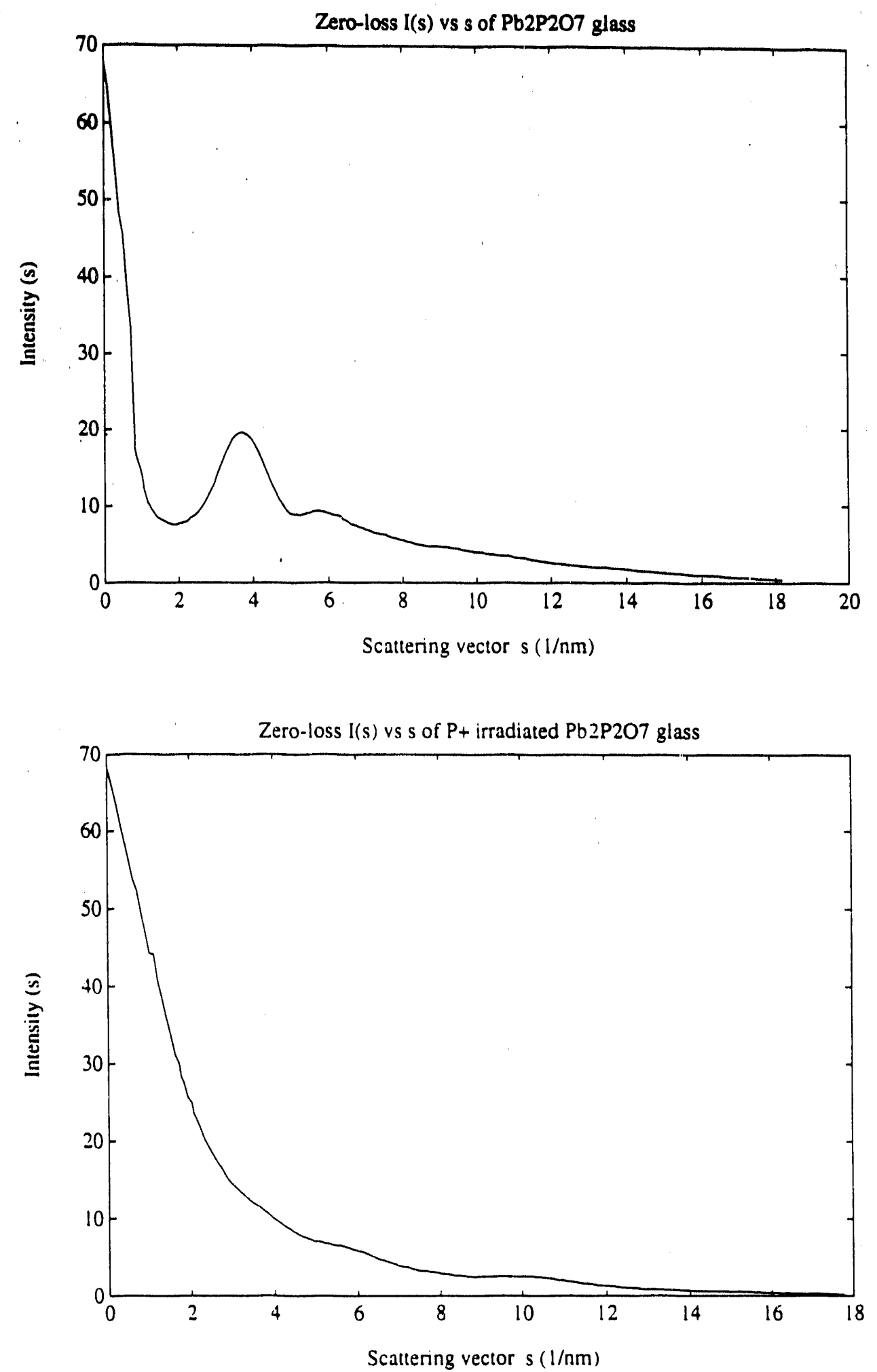

Fig. 22. Zero-loss STEM diffraction profiles for unirradiated and $\mathrm{P}^{+}$-implanted $\mathrm{Pb}_{2} \mathrm{P}_{2} \mathrm{O}_{7}$ glass. 

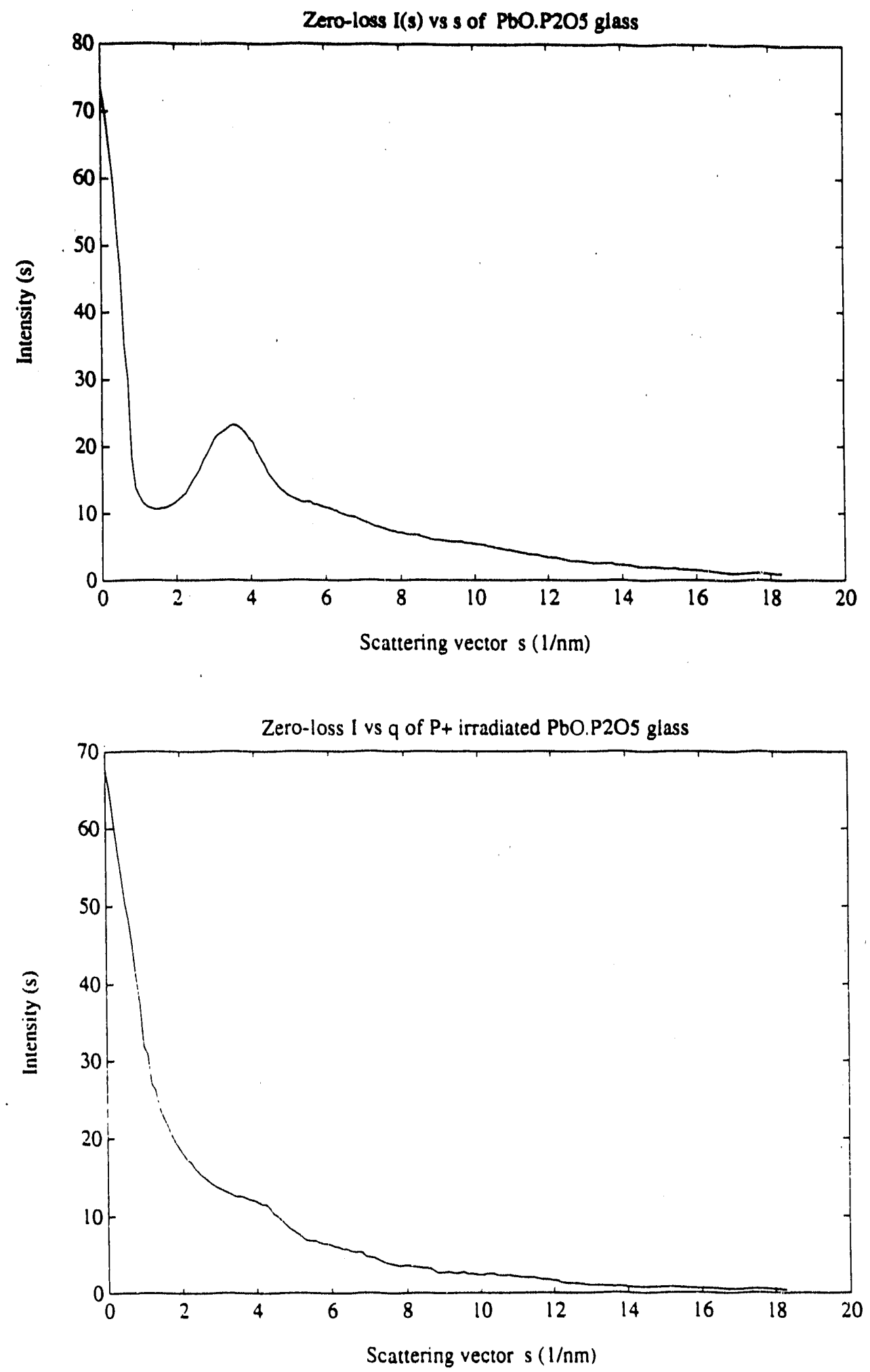

Fig. 23. Zero-loss STEM diffraction profiles for unirradiated and $\mathrm{P}^{+}$-implanted $\mathrm{PbO} \cdot \mathrm{P}_{2} \mathrm{O}_{5}$ glass. 


\section{REFERENCES}

1. F.W. Clinard and L. W. Hobbs, "Radiation Effects in Non-Metals," Chapter 7 of Physics of Radiation Effects in Crystals, ed. R.A. Johnson and A.N. Orlov, Elsevier Science Publishers, Amsterdam, 1986, pp. 387-471.

2. OBES/DMS Contractors' Meeting on Radiation Effects, 5-6 August 1986, Los Alamos National I boratory, Los Alamos, NM. Los Alamos Report LA-UR-86-4085 (1986).

3. IEA Workshop on the Basic Understanding of Radiation Effects in Inorganic Insulators for Fusion Applications, 13 September 1986, San Lorenzo de El Escorial, Madrid, Spain.

4. OBES/DMS Contractor's Meeting on Radiation Effects, 29-30 September 1988, Chicago, IL; Los Alamos Report LA-UR-3233 (1988).

5. W.J. Weber, L.K. Mansur, F.W. Clinard, Jr. and D.M. Parkin, "Radiation Effects on Materials in High-Radiation Environments: A Workshop Summary," Pacific Northwest Laboratories Report PNL-SA-1933 (April 1981); J. Nucl. Mater. (in press, 1991).

6. L.W. Hobbs, "Electron Beam Sensitivity in Inorganic Structures," Ultramicroscopy 23 (1987) 339-44.

7. M.N. Kabler and R.T. Williams, "Vacancy-Interstitial Pair Production via Electron Hole Recombination in Halide Crystals," Phys. Rev. B18 (1978) 1948-60.

8. L.W. Hobbs and M.R. Pascucci, "Radiolysis and Defect Structure in ElectronIrradiated $\alpha$-Quartz," J. Physique 41 [C6] (1980) 237-42.

9. R.C. Ewing, B.C. Chakomakos, G.R. Lumpkin and T. Murakami, "The Metamict State," MRS Bulletin (May 16/June 15, 1987) 58-66.

10. C.J. McHargue, G.C. Farlow, C.W. White, J.M. Williams, B.R. Appleton and H. Naramoto, "The Amorphization of Ceramics by Ion Beams," Mat. Sci. Eng. 69 (1985) $123-27$.

11. F.L. Vook and H.J. Stein, "Relation of Neutron to Ion Damage Annealing in Si and Ge," Rad. Effects 2 (1969) 23-30.

12. D.E. Luzzi and M. Meshii, "The Crystalline to Amorphous Transition of Intermetallic Compounds under Electron Irradiation--A Review," Res. Mechanica 21 (1987) 207-47. 
13. E. Lell, N.J. Kreidl and J.R. Hensler, "Radiation Effects in Quartz, Silica and Glasses," in Progress in Ceramic Science 4, ed. J. E. Burke (Pergamon Press, New York, 1966), p. 1-94.

14. J.C. Phillips, "The Physics of Glass," Physics Today (February 1982) 27-33.

15. L.A. Christee, J.F. Gibbons and T.W. Sigmon, "Displacement Criterion for Amorphization of Silicon During Ion Implantations," J. Appl. Phys. 52 (1981) 7143-46.

16. C.W. White, G.C. Farlow, C.J. McHargue, P.S. Sklad, M.P. Angelini and B.R. Appleton, "Formation of Amorphous Layers in $\mathrm{Al}_{2} \mathrm{O}_{3}$ by Ion Implantation, Nucl. Instrum. Methods Phys. Res. B7-8 (1985) 473-78.

17. C.J. McHargue, P.S. Sklad and C.W. White, "The Structure of Ion Implanted Ceramics," Nucl. Instrum. Methods Phys. Res. B46 (1990) 79-88.

18. J. Rankin, L.W. Hobbs, L.A. Boatner and C.W. White, "An In-Situ Annealing Study of Lead-Implanted Single Crystal Calcium Titanate," Nucl. Instrum. Methods Phys. Res. B32 (1988) 28-31.

19. C.W. White, L.A. Boatner, P.S. Sklad, C.J. McHargue, J. Rankin, G.C. Farlow and M.J. Aziz, "Ion Implantation and Annealing of Crystalline Oxides and Ceramic Materials," Nucl. Instrum. Methods Phys. Res. B32 (1988) 11-22.

20. G.R. Lumpkin and R.C. Ewing, " $\alpha$-Decay Damage and the Aperiodic Structure of Pyrochlore," Phys. Chem. Minerals 16 (1988) 2.

21. R.C. Ewing, B.C. Chakonmakos, G.R. Limpkin, T. Murakami, R.B. Greegor and F.W. Lytle, "Metamict Minerals: Natural Analogues for Radiation Damage Effects in Ceramic Nuclear Waste Forms," Nucl. Instrum. Methods Phys. Res. B32 (1988) 487 97.

22. W.J. Weber, J.W. Wald and Hj. Matzke, "Effects of Self-Irradiation in Cm-Doped $\mathrm{Gd}_{2} \mathrm{Ti}_{2} \mathrm{O}_{7}$ and $\mathrm{CaZrTi}_{2} \mathrm{O}_{7}$," J. Nuclear Mat. 138 (1986) 196-209.

23. R.C. Ewing and T.J. Headley, "Alpha-Recoil Damage in Natural Zirconolite $\left(\mathrm{CaZrTi}_{2} \mathrm{O}_{7}\right)$, J. Nucl. Mater. 119 (1983) 102-09.

24. F.W. Clinard, Jr., "Review of Self-Irradiation Effects in Pu-Substituted Zirconolite," Ceram. Bull. 65 (1986) 1181-87.

25. H.D. Holland and D. Gottfried, "The Effect of Nuclear Radiation on the Structure of Zircon," Acta Cryst. 8 (1955) 291-300. 
26. B.C. Chakoumakos, T. Muraklami, G.R. Lumpkin and R.C. Ewing, "Alpha-Decay Induced Fracturing in Zircon: The Transition from the Crystalline to the Metamict State," Science 236 (1987) 1556-59.

27. W.J. Weber, "Radiation Induced Defects and Amorphization in Zircon," J. Mater. Res. 5 (1990) 2687-97.

28. W.J. Weber, "Self-Radiation Damage and Recovery in Pu-Doped Zircon," Rad. Effects 115 (1991) 341-49.

29. M.R. Pascucci, J.L. Hutchison and L.W. Hobbs, "The Metamict Transition in $\alpha$ Quartz," Rad. Effects 74 (1983) 219-26.

30. D.R. Veblen and P.R. Buseck, "Radiation Effects on Minerals in the Electron Microscope," Proc. 41st Ann. Meeting EMSA, ed. G.W. Bailey, San Francisco Press, 1983, pp. 350-53.

31. L.A. Bursill, E.A. Lodge and J.M. Thomas, "Zeolite Structures as Revealed by HighResolution Electron Microscopy," Nature 286 (1980) 111-113.

32. L.W. Hobbs, "Murphy's Law and the Uncertainty of Electron Probes," Scanning Microscopy, Supplement 4 (1990) 171-183.

33. F.F. Morehead, Jr., and B.L. Crowder, "A Model for the Formation of Amorphous Si by Ion Bombardment," Rad. Effects 6 (1970) 27-32.

34. W.J. Weber, "Radiation Damage in a Rare-Earth Silicate with the Apatite Structure," J. Amer. Ceram. Soc. 65 (1982) 544-48.

35. W.J. Weber and $\mathrm{Hj}$. Matzke, "Effects of Radiation on Microstructure and Fracture Properties of $\mathrm{Ca}_{2} \mathrm{Nd}_{8}\left(\mathrm{SiO}_{4}\right)_{6} \mathrm{O}_{2}$," Mater. Lett. 5 (1986) 9-16.

36. C.J. McHargue and J.M. Williams, "Structure and Properties of Silicon Carbide Implanted with Chromium," Metastable Materials Formed by Ion Implantation, ed. S.T. Picraux and W.J. Choyke, Elsevier Science Publishing, New York, 1982, pp. 303-09.

37. Hj. Matzke, "Radiation Damage in Crystalline Insulators, Oxides and Nuclear Fuels," Rad. Effects 64 (1982) 3-33.

38. H.M. Naguib and R. Kelly, "Criteria for Bombardment-Induced Structural Changes in Non-Metallic Solids," Rad. Effects 25 (1975) 1-12.

39. Hj. Matzke, "Radiation Effects in Nuclear Materials," Nucl. Instrum. Methods Phys. Res. B32 (1988) 455-70. 
40. A.R. Cooper, "Zachariasen's Rules, Madelung Constant and Network Topology," Phys. Chem. Glasses 19 (1978) 60-68.

41. D.E. Luzzi and M. Meshii, "Chemical Disordering in Amorphization," J. Less Common Metals 140 (1987) 193-201.

42. R. Webb and G. Carter, "Difficulties in Deducing Disordering Mechanisms from Experimental Studies of Disorder-Ion Fluence Functions in Ion Irradiation of Semiconductors," Rad. Eff. 42 (1979) 159-68.

43. R.S. Averback and D.N. Seidman, "Energetic Displacement Cascades and their Roles in Radiation Effects," Mat. Sci. Forum 15-18 (1987) 963-83.

44. S.D. Berger, I.G. Salisbury, R.H. Milne, D. Imeson and C.J. Humphreys, "Electron Energy Loss Spectroscopy Studies of Nanometer-Scale Structures in Alumina Produced by Intense Electron-Beam Irradiation," Phil. Mag. B55 (1987) 669-81.

45. W.A. Coughlan and F.W. Clinard, Jr., "Modelling of Irradiation-Induced Amorphization in a Titanate Ceramic," J. Less Common Metals (1988).

46. F.W. Clinard, Jr., D.E. Peterson, D.L. Rohr and L.W. Hobbs, "Self-Irradiation Effects in ${ }^{238}$ Pu-Substituted Zirconlite: I. Temperature Dependence of Damage," J. Nucl. Mater. 126 (1984) 245-54.

47. W.A. Deer, R.A. Howie and J. Zussman, Rock Forming Minerals, Vol. 4, Framework Silicates, Longmans, Green \& Co., London, 1962, pp. 180-227.

48. M.R. Pascucci, "Crystalline to Non-Crystalline Transformation of Irradiated Quartz," Ph.D. Thesis, Case Western Reserve University, Cleveland, OH, 1984.

49. R. A. Hemley, A.P. Jephcoat, M.K. Mao, L.C. Ming and M.H. Manghrani, "Pressure Induced Amorphization of Crystalline Silica," Nature 334 (1988) 52-54.

50. H. Inui, H. Mori, T. Sakata and H. Fujita, "Electron Irradiation Induced Crystallineto-Amorphous Transition in Quartz Single Crystals," J. Non-Crystall. Solids 116 (1990) 1-15.

51. D.L. Griscom, "Point Defects and Radiation Damage. Processes in $\alpha$-Quartz," Proc. 33rd. Freq. Control Symp., Electronic Industries Assoc., Washington, D.C., 1979, pp. 98-109.

52. U. Jain, A.C. Powell and L.W. Hobbs, "Simulation of the Crystal-to-Amorphous Transformation in Irradiated Quartz," MRS Symp. Proc. 209 (1991) 201-06. 
53. Y. Beppu, Computation News of Nagoya University 9 (1978) 123 [in Japanese: our undergraduate research assistant, Mr. Adam Powell, fortunately speaks Japanese].

54. W.W. Meier and H. Villiger, "Die Methnde der Abstandsverfeinerung zur Bestimmung de Atomkoordinaten idealsierter Gerüstrukturen," Z. Kristallogr. 129 (1969) 419-23.

55. C.S. Marians and L.W. Hobbs, "Network Properties of Crystalline Polymorphs of Silica," J. Non-Crystall. Solids 124 (1990) 242-53.

56. C.S. Marians and L.W. Hobbs, "Local Structure of Silica Glass," J. Non-Crystall. Solids. 119 (1990) 269-82.

57. C.S. Marians and J.K. Burdett, "Geometric Constraints: A Refined Model for the Structure of Silica Glass," J. Non-Crystall. Solids 124 (1990) 1-21.

58. W.H. Zachariasen, "The Atomic Arrangements in Glass," J. Amer. Chem. Soc. 54 (1932) 3841-51.

59. A.A. Lebedev, Trudy Gosud. Optichesk Inst. 2 (1921) 10.

60. C.H.L. Goodman, "Strained Mixed-Cluster Model for Glass Structure," Nature 257 (1985) 370-72.

61. R. Hosemann, M. Heutschel, A. Lange, B. Uther and R. Brüvhner, "Dreidimensonale Analyse der parakristallinen Struktur von Kieselglas," Z. Kristall. 169(1984) 13-33.

62. A.C. Wright, R.A. Hulne, D.I. Grimely, R.N. Sinclair, S.W. Martin, D.L. Price and F.L. Galeener, "The Structure of Some Amorphous Network Solids Revisited," J. Non-Crystall. Solids 42 (1980) 69-86.

63. A.C. Wright, G.A.N. Connell and J.W. Allen, "Amorphography and the Modelling of Amorphous Solid Structures by Geometric Transformations," J. Non-Crystall. Solids 42 (1980) 69-86.

64. A.C. Wright, G. Etherington, J.A.E. Desa, R.N. Sinclair, G.A.N. Connell and J.K. Mikkelsen, Jr., "Neutron Amorphography," J. Non-Crystall. Solids 49 (1982) 63-102.

65. C.S. Marians, "A Language for the Study of Silica Networks," Ph.D. Thesis, M.I.T., Cambridge, MA, 1988.

66. P.K. Gupta and A.R. Cooper, "Topologicaliy Disordered Networks of Rigid Polytopes," J. Non-Crystall. Solids 123 (1990) 14-21. 
67. D.L. Evans and S.V. King, "Random Network Model of Vitreous Silica," Nature 22 (1966) 1353-54.

68. S.V. King, "Ring Configurations in a Random Network Model of Vitreous Silica," Nature 213 (1967) 1112-13.

69. R.J. Bell and P. Dean, "The Structure of Vitreous Silica: Validity of the Random Network Theory," Nature 212 (1966) 1354-56.

70. L.F. Gladden, "Medium Range Order in v-SiO 2 ," J. Non-Crystall. Solids 119 (1990) 318-30.

71. C.S. Marians and L.W. Hobbs, "The Phase Structure of Aperiodic $\mathrm{SiO}_{2}$ as a Function of Network Topology," J. Non-Crystall. Solids 106 (1988) 309-12.

72. J.H. Konnert and J. Karle, "Tridymite-like Structure in Silica Glass," Nature 236 (1972) 92-94.

73. L.U. Ogbuji, T.E. Mitchell and A.H. Heuer, "The $\beta \rightarrow \alpha$ Transformation in Polycrystalline SiC: III, The Thickening of $\alpha$ Plates," J. Amer. Ceram. Soc. 64 (1981) 91-99.

74. T. Ekstrom and R.J. Telley, "The Formation of Cristobalite in Evacuated Silica Ampoules and the Transformation of Cristobalite to Amorphous Silica," J. Cryst. Growth 38 (1977) 197-205.

75. K. Furukawa, "The Radial Distribution Curves of Liquids by Diffraction Methods," Rep. Prog. Phys. 25 (1962) 395-440.

76. R.L. Mozzi, An X-Ray Study of the Structure of Glass, Ph.D. Thesis, MIT, 1968.

77. A.C. Wright, "The Structure of Amorphous Solids by X-Ray and Neutron Diffraction," Adv. Struc. Res. Diff. Methods 5 (1974) 1-84.

78. A.C. Wright and A.J. Leadletter, "Diffraction Studies of Glass Structure," Phys. Chem. Glasses 17 (1976) 122-45.

79. C.W.B. Grigson, "Studies of Thin Polycrystalline Films by Electron Beams," Adv. Electron. and Electron Phys. Suppl. 4 (1968) 187-290.

80. D.B. Dove, "Electron Diffraction Analysis of the Local Atomic Order in Amorphous Films," Phys. Thin Films 7 (1973) 1-41.

81. D.B. Dove and P.N. Denbigh, Proc. 6th. Int. Cong. Elec. Microsocpy, 1966, p. 67. 
82. L.H. Germer and A.H. White, "Electron Diffraction Studies of Thin Films. II. Amorphous Powder Patterns Produced by Small Crystals," Phys. Rev. 60 (1941) 44754.

83. C.W.B. Grigson and E. Barton, "The Development of the Face-Centred Cubic Interference Functions as Crystals Grow," Brit. J. Appl. Phys. 18 (1967) 175-83.

84. L.I. Tatarinova, "Electron Diffraction Study of Amorphous Antimony Sulphide," Sov. Phys.-Crystallogr. 2 (1957) 251-58.

85. M.V. Coleman and D.J.D. Thomas, "The Structure of Silicon Oxide Films," Phys. Stat. Sol. 22 (1967) 593-602.

86. J. Karle and J.H. Konnert, "Analysis of Diffraction from Amorphous Materials and Applications," Trans. Amer. Cryst. Assoc 10 (1974) 29-43.

87. P. D'Anotonio, P. Moore, J.H. Konnert and J. Karle, "Electron Diffraction Analysis of Amorphous Materials," Trans. Amer. Cryst. Assoc. 13 (1977) 43-66.

88. S. Fujime, "Electron Diffraction at Low Temperature II. Radial Distribution Analysis of Metastable Structure of Metal Films Prepared by Low Temperature Condensation," Jpn. J. Appl. Phys. 5 (1966) 764-77.

89. A.R. Pelton, "Structural Studies of Small Amorphous Volumes by Electron Diffraction," EMSS Proc. 46 (1988) 454-55.

90. P. Moine, A.R. Pelton and R. Sinclair, "Structural Determination of Small Amorphous Volumes by Electron Diffraction," J. Non-Crystall. Solids 101 (1988) 213222.

91. C.W.B. Grigson, "High-Speed Direct-Recording System for Electron Diffraction," Nature 192 (1961) 647-48.

92. C.W.B. Grigson, "A Scanning Electron Diffraction System," J. Japan Phys. Soc. 17 Suppl. II (1962) 298-300.

93. C.W.B. Grigson, D.B. Dove and G.R. Stilw ell, "Some Applications of an Improved Scanning Electron Diffraction System," Nature 205 (1965) 1198-.

94. M.F. Tompsett and C.W.B. Grigson, "Scanning Electron Diffraction of Solids," Nature 206 (1969) 923-24.

95. J. Chang and D.B. Dove, 7th Inter. Congr. Electron Microsc., Vol. 2, Grenoble, 1970, p. 183. 
96. J.F. Graczyk, Selected Studies in Scanning Electron Diffraction, Ph.D. Thesis, MIT, 1968.

97. S.C. Moss and J.F. Graczyk, "Evidence of Voids with the As-Deposited Structure of Glassy Silicon," Phys. Rev. Lett. 23 (1969) 1167-71.

98. J.F. Graczyk and P. Chaudhari, "A Scanning Electron Diffraction Study of Vapor Deposited and Ion Implanted Thin Films of Ge (I)," Phys. Stat. Sol. (b)58 (1973) 16379.

99. J.F. Graczyk, "Structure of Glow Discharged Amorphous Silicon," Phys. Stat. Sol. (a)55 (1979) 231-42.

100. D.J.H. Cockayne and D.R. McKenzie, "Electron Diffraction Analysis of Polycrystalline Amorphous Thin Films," Acta Cryst. A44 (1988) 870-78.

101. A. Sprout, D.R. McKenzie and D.J.H. Cockayne, "Structural Studies of Hydrogenated Amorphous Silicon-Carbon Alloys," Phil. Mag. B54 (1986) 113-31.

102. Z.Q. Liu, D.R. McKenzie, D.J.H. Cockayne and D.M. Dwarte, "Electron Diffraction Study of the Structrue of Boron- and Phosphorus-Doped Hydrogenated Amorphous Silicon," Phil. Mag. B57 (1988) 753-71.

103. W.G. Sainty, D.R. McKenzie, P.J. Martin, R.P. Netterfield, D.J.H. Cockayne and D.M. Dwarte, "The Structure and Properties of Ion-beam Synthesized Boron Nitride Films, J. Appl. Phys. 64 (1988) 3980-6.

104. N.F. Mott and H.S.W. Massey, The Theory of Atomic Collisions, Oxford University Press, 1965.

105. A.L. Patterson, "A Fourier Series Method for the Determination of the Components of Interatomic Distances in Crystals," Phys. Rev. 46 (1934) 372,-76.

106. A.L. Patterson, "A Direct Method for the Determination of the Components of Interatomic Distances in Crystals," Z. Krist. 90 (1935) 517-42.

107. R.W. James, Optical Principles of the Diffraction of X-Rays, G. Bell and Sons, 1962.

108. P. Debye, "Zerstreuung von Röntgenstrahlen," Ann. Physik 46 (1961) 809-23.

109. B.K. Vainshtein, "On the Theory of the Radial Distribution Method." Soviet Phys. Crystallogr. 2 (1967) 24-32. 
110. F. Zernike and J.A. Prins, "Die Beugung von Röntgenstrahlen in Flüssigkeiten als Effekt der Molekülanordnung," Z. Phys. 41 (1927) 184-94.

111. B.E. Warren, X-Ray Diffraction, Dover, 1990.

112. D.T. Keating, "Interpretation of the Neutron or X-ray Scattering froma Liquid-Like Binary," J. Appl. Phys. 34 (1963) 923-25.

113. B.E. Warren, H. Krutter and O. Morningstar, "Fourier Analysis of X-ray Patterns of Vitreous $\mathrm{SiO}_{2}$ and $\mathrm{B}_{2} \mathrm{O}_{3}$," J. Amer. Cer. Soc. 19 (1936) 202-06.

114. R. Kaplow, S.L. Strong and B.L. Averbach, "Radial Density Functions for Liquid Mercury and Lead," Phys. Rev. 138 (1965) A1336-45.

115. Y. Waseda, "Novel Application of Anomalous (Resonance) X-ray Scattering for Structural Characterization of Disordered Materials," Lecture Notes in Physics, Vol. 204, Springer-Verlag, 1985.

116. B.E. Warren, R.L. Mozzi, "Multiple Scattering of X-rays by Amorphous Samples," Acta Cryst. 21 (1966) 459-61.

117. J.M. Cowley, Diffraction Physics, North-Holland, 1981.

118. J. Gjønnes, "Quantitative Treatment of Multiple Scattering Effect in Continuous Electron Diffraction Curves," Acta Cryst. 12 (1959) 976-80.

119. I.L. Karle and J. Karle, "Internal Motion and Molecular Structure Studies by Electron Diffraction III. Structure of $\mathrm{CH}_{2}$ and $\mathrm{CF}_{2} \mathrm{CF}_{2}$,"J. Chem. Phys 18 (1950) 96371.

120. L.D. Marks, "Linear Imaging and Diffraction of an Amorphous Film," Ultramicroscopy 25 (1988) 85-87.

121. G.R. Anstis, Z. Liu and M.R. Lake, "Investigation of Amorphous Materials by Electron Diffraction - The Effects of Multiple Scattering," Ultramicroscopy 26 (1988) 65-70.

122. P.H. Denbigh and C.W.B. Grigson, "Scanning Electron Diffraction with Energy Analysis," J. Sci. Instrum. 42 (1965) 305-11.

123. J.F. Graczyk and S.C. Moss. "Scanning Electron Diffraction Attachment with Energy Filtering," Rev. Sci. Instrum. 40 (1969) 424-33. 
124. L. Reimer, I. Fromm and I. Naundorf, "Electron Spectroscopic Diffraction," Ultramicroscopy 32 (1990) 80-91.

125. L. Reimer, I. Fromm and R. Rennekamp, "Operational Models of Electron Spectroscopic Imaging and Electron Energy Loss Spectroscopy in a Transmission Electron Microscope," Ultramicroscopy 24 (1988) 339-54.

126. J.M. Konnert and J. Karles, "Crystalline Ordering in Silica and Germania Glasses," Science 179 (1973) 177-79.

127. J. Biscoe, A. Pincus, C. Smith, Jr. and B.E. Warren, "X-ray Study of Lime-Phosphate and Lime-Borate Glass," J. Amer. Ceram. Soc. 24 (1941) 116-19.

128. G. Wignall, R. Rothon, G. Longmann and G. Woodward, "The Study of Amorphous Aluminum Phosphate by Radial Distribution Functions Derived from X-ray Diffraction," J. Mater. Sci. 12 (1977) 1039-99.

129. D.F. Mullica, H.O. Perkins, D.A. Grossie, L.A. Boatner and B.C. Sales, "Structure of Dichromate-Type Lead Pyrophosphate, $\mathrm{Pb}_{2} \mathrm{P}_{2} \mathrm{O}_{7}$," J. Solid State Chem. 62 (1986) 371-6.

130. J.R. Van Wazer and K.A. Holst, "Structure and Properties of the Condensed Phosphates. I. Some General Considerations about Phosphoric Acids," J. Amer. Chem. Soc. 24 (1950) 639-63.

131. R.S. Brazell, R.W. Holmberg and J.H. Moneyhun, "Application of High Performance Liquid Chromatography - Flow Injection Analysis for Determination of Polyphosphoric Acids in Phosphorus Smokes," J. Chromatogr. 290 (1984) 163-72.

132. B.C. Sales, M.M. Abraham, J.B. Bates and L.A. Boatner, "Structural Properties of Lead-Iron Phosphate Glasses," J. Non-Crystall. Solids 71 (1985) 103-112.

133. B.C. Sales, R.S. Ramsey, J.B. Bates and L.A. Boatner, "Investigation of the Structural Properties of Lead-Iron Phosphate Glasses Using Liquid Chromatography and Raman Scattering Spectroscopy," J. Non-Crystall. Solids 87 (1986) 137-158.

134. G.N. Greaves, S.J. Gurman, L.F. Gladden, C.A. Spence, P. Cox, B.C. Sales, L.A. Boatner and R.N. Jenkins, "A Structural Basis for Corrosion Resistance of Lead-IronPhosphate Glasses: An X-ray Absorption Spectroscopy Study," Phil. Mag. B58 (1988) 271-83.

135. B.C. Sales, J.O. Ramsey and L.A. Boatner, "Structural Alterations in the Amorphousto-Crystalline Transformation of Lead Pyrophosphate," Phys. Rev. Letters 59 (1987) 1718-21. 
136. B.C. Sales and L.A. Boatner, "Lead-Iron Phospate Glass: A Stable Storage Medium for High-Level Nuclear Waste," Science 226 (1984) 45-48.

137. B.C. Sales and L.A. Boatner, "Physical and Chemical Characteristics of Lead-Iron Phosphate Nuclear Waste Glass," J. Non-Crystall. Solids 79 (1986) 83-116.

138. B.C. Sales, J.O. Ramey, L.A. Boatner and J.C. McCallum "Structural Inequivalence of the Ion-Damage-Produced Amorphous State and the Glass State in Lead Pyrophosphate," Phys. Rev. Lett. 62 (1989) 1138-41.

139. B.C. Sales, J.O. Ramey, J.C. McCallum and L.A. Boatner, "Structural Differences between the Glass State and Ion-Beam-Amorphized States of Lead Pyrophosphate," J. Non-Crystall. Solids 126 (1990) 179-93.

140. J.R. Parks and J.R. Van Wazer, "Structure and Properties of the Condensed Phosphates, XII. Reorganization Theory and Some Applications," J. Chem. Phys. 79 (1957) 4890-97.

141. J.P. Biersack and L.G. Haggmark, "S Monte Carlo Computer Program for the Thransport of Energetic Ions in Amorphous Targets," Nucl. Instrum. Methods 174 (1980) 257-69. [We used version TRIM-90.]

142. T. Maruyama and L.W. Hobbs, "TEM Investigation of Neurton-Irradiated Quartz," 90th Ann. Meet. American Ceramic Society, Cincinnati, OH, 3 May 1988, paper 3JV88; Amer. Ceram. Soc. Bull. 67 (1988) 574.

143. A.N. Sreeram, A.K. Varshneya, R. Kudesia and S.S. Bayya, "EXAFS Studies of Binary Ge-Se Chalcogenide Glasses", submitted to J. Non-Crystall. Solids (June 1991).

144. A.N. Sreeram, D.R. Swiler and A.K. Varshneya, "Gibbs-DiMarzio Equation to Describe the Glass Transition Temperature Trends in Multicomponent Chalcogenide Glasses," J. Non-Crystall. Solids 127 (1991) 287-297.

145. A.N. Sreeram, A.K. Varshneya and D.R. Swiler, "Molar Volume and Elastic Properties of Multicomponent Chalcogenide Glasses," J. Non-Crystall. Solids 128 (1991) 294-309.

146. A.N. Sreeram, A.K. Varshneya and D.R. Swiler, "Microhardness and Indentation Toughness versus Average Coordination Number in Isostructural Chalcogenide Glass Systems," J. Non. Crystall. Solids 130 (1991) 225-235.

147. K.S. Hong, R.F. Speyer and R.A.Condrate, "Infrared Reflectance and Transmission Spectra of II-IV-V Semiconducting Compounds: Ce GeAs, "J. Phys. Chem. Solids 51 (1990) 969-76. 
148. A.N. Sreeram, R. Kudesia, A.K. Varshneya and R.A. Condrate, "Structural Trends in Multicomponent Ge-Sb-As-Se-Te Chalcogenide Glasses Using Fourier Transform Infra-Red Spectroscopy and Their Similarities and Dissimilarities With Relevant Bivalent Crystals," unpublished.

149. J.H. Gibbs and E.A. DiMarzio, "Glass Transition and Glassy State," J. Chem. Phys. 28 (1958) 373-38.

150. J.B. Pethica, R. Hutchings and W.C. Oliver, "Hardness Measurements at Penetration Depths as Small as 20 nm," Phil. Mag. A48 (1983) 593. 


\section{PUBLICATIONS}

The following publications arising from the research program described have appeared in the first two years of the present grant period.

1. Uma Jain, Adam C. Powell and Linn W. Hobbs, "Simulation of Crystal-toAmorphous Transition in Irradiated Quartz," MRS Symp. Proc. 209 (1991) 201-06.

2. L. W. Hobbs, "Murphy's Law and the Uncertainty of Electron Probes," Scanning Microscopy Supplement 4 (1991) 171-84.

3. Carol S. Marians and Linn W. Hobbs, "Local Structure of Silica Glasses," J. NonCrystall. Solids 119 (1990) 269-82.

4. Carol S. Marians and Linn W. Hobbs, "Network Properties of Crystalline Polymorphs of Silica," J. Non-Crystall. Solids 124 (1990) 242-53.

5. Carol S. Marians and Jeremy K. Burdett, "Geometric Constraints: A Refined Model for the Structure of Silica Glass," J. Non-Crystall. Solids 124 (1990) 1-21.

6. Linn W. Hobbs and Carol S. Marians, "Combinatorial Geometrics of Network Silicas," [invited contribution] Trans. Amer. Crystallographic Assoc. 27 (in press, 1991).

C: \hobbs \proposal.doe \techrpt.'92 

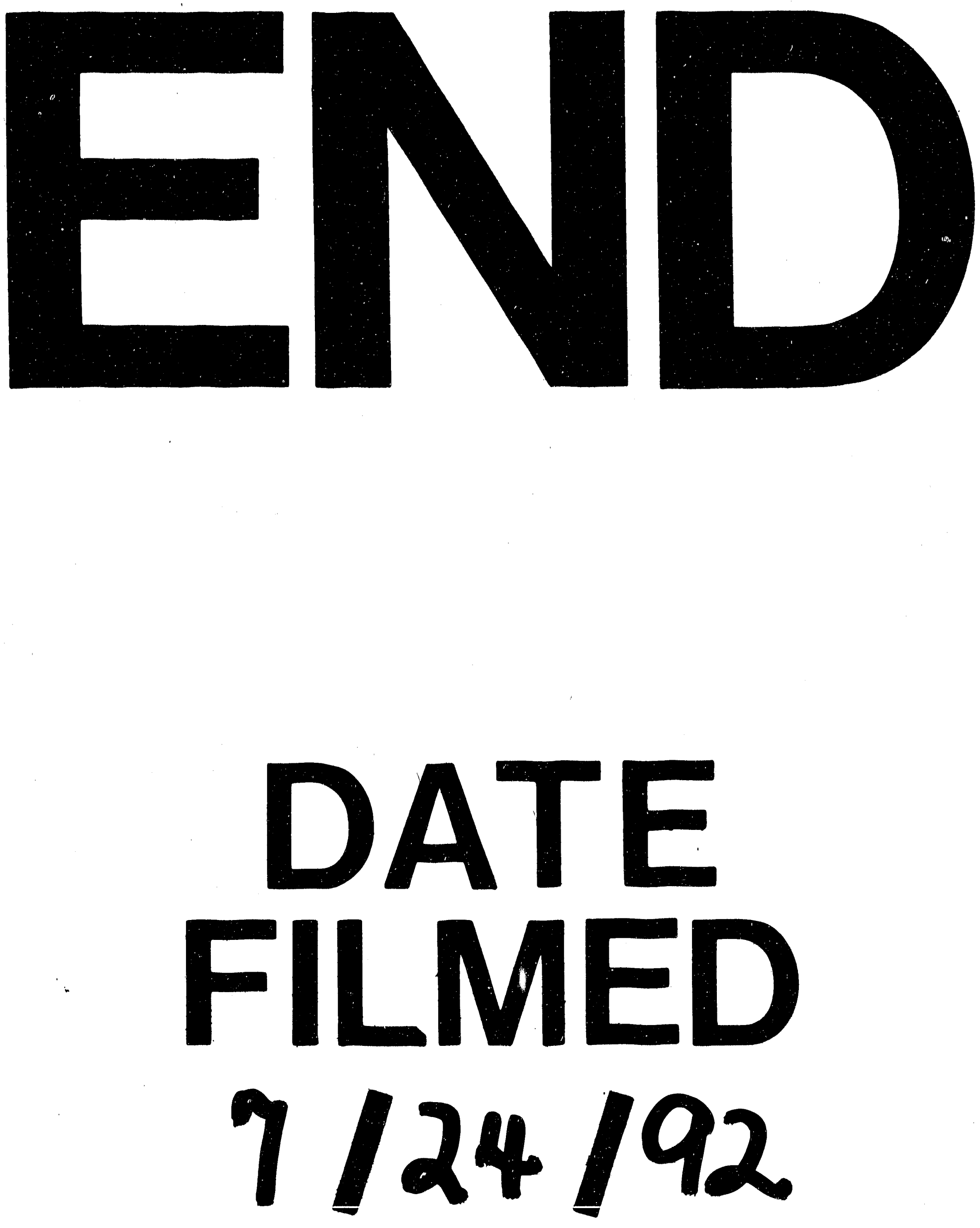
